\title{
Selection of the Root Endophyte Pseudomonas brassicacearum CDVBN10 as Plant Growth Promoter for Brassica napus L. Crops
}

\author{
Alejandro Jiménez-Gómez ${ }^{1,2,+} \mathbb{D}^{\mathbb{D}}$, Zaki Saati-Santamaría ${ }^{1,2} \mathbb{D}^{\mathbb{D}}$, Martin Kostovcik ${ }^{3,4}$, \\ Raúl Rivas ${ }^{1,2,5} \mathbb{D}$, Encarna Velázquez ${ }^{1,2,5}$, Pedro F. Mateos ${ }^{1,2,5}$, Esther Menéndez ${ }^{1,2,5,6, *(\mathbb{D})}$ and \\ Paula García-Fraile 1,2,5,*(D) \\ 1 Microbiology and Genetics Department, University of Salamanca, 37007 Salamanca, Spain; \\ alexjg@usal.es (A.J.-G.); zakisaati@usal.es (Z.S.-S.); raulrg@usal.es (R.R.); evp@usal.es (E.V.); \\ pfmg@usal.es (P.F.M.) \\ 2 Spanish-Portuguese Institute for Agricultural Research (CIALE), Villamayor, 37185 Salamanca, Spain \\ 3 Department of Genetics and Microbiology, Faculty of Science, Charles University, 12844 Prague, \\ Czech Republic; kostovci@biomed.cas.cz \\ 4 BIOCEV, Institute of Microbiology, the Czech Academy of Sciences, 25242 Vestec, Czech Republic \\ 5 Associated R\&D Unit, USAL-CSIC (IRNASA), Villamayor, 37185 Salamanca, Spain \\ 6 MED-Mediterranean Institute for Agriculture, Environment and Development, Institute for Advanced \\ Studies and Research (IIFA), Universidade de Évora, Pólo da Mitra, Ap. 94, 7006-554 Évora, Portugal \\ * Correspondence: esthermenendez@uevora.pt (E.M.); paulagf81@usal.es (P.G.-F.) \\ + Present address: School of Humanities and Social Sciences, University Isabel I, 09003 Burgos, Spain.
}

Received: 5 October 2020; Accepted: 12 November 2020; Published: 15 November 2020

\begin{abstract}
Rapeseed (Brassica napus L.) is an important crop worldwide, due to its multiple uses, such as a human food, animal feed and a bioenergetic crop. Traditionally, its cultivation is based on the use of chemical fertilizers, known to lead to several negative effects on human health and the environment. Plant growth-promoting bacteria may be used to reduce the need for chemical fertilizers, but efficient bacteria in controlled conditions frequently fail when applied to the fields. Bacterial endophytes, protected from the rhizospheric competitors and extreme environmental conditions, could overcome those problems and successfully promote the crops under field conditions. Here, we present a screening process among rapeseed bacterial endophytes to search for an efficient bacterial strain, which could be developed as an inoculant to biofertilize rapeseed crops. Based on in vitro, in planta, and in silico tests, we selected the strain Pseudomonas brassicacearum CDVBN10 as a promising candidate; this strain produces siderophores, solubilizes $\mathrm{P}$, synthesizes cellulose and promotes plant height in 5 and 15 days-post-inoculation seedlings. The inoculation of strain CDVBN10 in a field trial with no addition of fertilizers showed significant improvements in pod numbers, pod dry weight and shoot dry weight. In addition, metagenome analysis of root endophytic bacterial communities of plants from this field trial indicated no alteration of the plant root bacterial microbiome; considering that the root microbiome plays an important role in plant fitness and development, we suggest this maintenance of the plant and its bacterial microbiome homeostasis as a positive result. Thus, Pseudomonas brassicacearum CDVBN10 seems to be a good biofertilizer to improve canola crops with no addition of chemical fertilizers; this the first study in which a plant growth-promoting (PGP) inoculant specifically designed for rapeseed crops significantly improves this crop's yields in field conditions.
\end{abstract}

Keywords: Pseudomonas; PGPB; bioinoculants; endophytes; bacterial microbiome; culturome; genome sequencing; Brassica napus 


\section{Introduction}

The FAO estimates that there will be 2.3 billion more people on the Earth in 2050, in a world already struggling to combat poverty and hunger. Thus, we need to increase our capability to produce food using the limited natural resources of our planet more efficiently while fighting climate change. Chemical fertilizers increase crop yields, but they have negative effects for human and animal health, contaminate soils and water, and their fabrication, which requires huge amounts of energy, contributes to resource depletion and global warming [1]. Moreover, the excessive or repetitive use of chemical fertilizers usually presents low efficiency in their use by plants because the soil biogeochemical cycles is often altered [2].

Alternatively, plant growth-promoting bacteria (PGPB), which are naturally occurring microbes that modulate plant growth due to their metabolic activities, can enhance crop yields when applied as biofertilizers [3-5]. PGPB can fix atmospheric nitrogen, produce siderophores and/or phytohormones, solubilize phosphorous and/or potassium and inhibit the growth of pathogenic microorganisms [6]. Within PGPB, endophytes are particularly interesting because, once inside the plant, they do not need to compete with the dense population of bacteria in the rhizosphere and they are protected from extreme abiotic conditions, so they have more chances to succeed when applied in the fields $[7,8]$.

Endophytes are part of the plant microbiome and play essential roles for its fitness and survival [9]. Many of these microorganisms are non-cultivable in routine laboratory conditions and thus, culture independent methods allow us to unravel the complete microbial diversity living within the plants. These endophytic microbiomes, as occurs in animals, interact with their host in essential functions [10-12]; hence, plant microbiome research highlights the importance of indigenous microbial communities for host phenotypes such as growth and health [13].

Brassica napus L. (rapeseed, canola) is an important crop due to its cultivation not only as a food resource (human and animal), but also for biodiesel production, being one of the most significant oilseed crops in temperate climates [14]. In Europe, rapeseed seeds are the primary source of oil for biodiesel production, its by-product being a high protein source for animal feeding [15]. However, rapeseed cultivation requires important amounts of chemical fertilizers [16], and therefore, alternatives that enable the reduction in chemical fertilization for a more sustainable crop are very desirable. This implies the use of biofertilizers, which include endophytic PGPB.

Thus, the design of an efficient bacterial endophytic inoculant for rapeseed crops which could increase rapeseed crop yields with no addition of chemical fertilizers is very desirable. For that purpose, it is necessary to study the members of the bacterial endophytic population, those members of the endophytic community which can be artificially cultured and thus biotechnologically produced and formulated.

In terms of plant growth-promoting (PGP) functionality, in vitro PGP mechanisms have been analyzed in just a few rhizospheric [17] or endophytic bacteria associated with B. napus plants [18,19]. In addition, the information about the effects of PGPB in rapeseed plants is scarce [18,20-23]. Taking advantage of next generation sequencing, PGPB genome sequence annotation and analysis allow in silico studies of the genetic potential of a bacterium to promote plant growth, including the discovery of specific PGP traits and/or pathways, such as tolerance to different biotic and abiotic stresses, heavy metal detoxifying activity or biological control potential [24].

These massive parallel sequencing techniques are becoming even more interesting when applied to elucidate the taxonomic composition and biological functions of the plant and soil microbiome when plants grow under field conditions, where they can be used to recreate the microbial communities' dynamics [25].

Based on the hypothesis that bacterial endophytes can be efficient biofertilizers when applied as inoculants in the fields, the aim of this work was to isolate and select a rapeseed bacterial endophyte with the potential to promote rapeseed growth and yields. For that, we obtained a collection of rapeseed endophytic bacteria and analyzed the potential of our isolates as plant growth promoters, through a screening of a few in vitro PGP mechanisms followed by the analysis of the in planta effect 
with several selected isolates, evaluating their capability to promote rapeseed seedling growth. Once we had selected the best-performing strains in planta, we obtained the genome sequences of the best PGP endophytic strains to deepen the study of their molecular machinery implicated in plant colonization and growth promotion. The in silico and in vivo assays allowed us to select one particular strain, which was inoculated in a field trial, showing for the first time a significant increase in rapeseed yields using a PGP bacterium inoculum. As a novelty, we analyzed the impact of the inoculation of the strain not only in the plant development and crop yields, but also on the root endophytic community.

\section{Materials and Methods}

\subsection{Isolation and Identification of Bacterial Isolates}

Rapeseed plants (B. napus cv rescator) in the phenological stage of rosette were collected in February 2017 from two agricultural soils located in the municipalities of Castellanos de Villiquera (CDV) (province of Salamanca) and Peleas de Arriba (PDA) (province of Zamora), both in Spain. Plants were extracted from the soils, kept refrigerated and shipped to the laboratory, where they were processed within two hours from the time of extraction.

To isolate rapeseed root bacterial endophytes, roots were excised carefully and washed in sterile Petri dishes containing sterile distilled water $(\times 10$ times) and then surface-disinfected by immersion in sodium hypochlorite ( $2 \%$ ) for $2 \mathrm{~min}$. After that, surface-disinfected roots were washed 5 times in sterile distilled water and dried with sterile filter paper. An aliquot of water from the last washing step of each sample after the disinfection protocol and a few entire disinfected roots were plated as disinfection controls. No bacterial growth was observed in those plates.

Surface-disinfected roots were smashed in a sterile mortar and the content was serially diluted with sterile distilled water. Then, $100 \mu \mathrm{L}$ of the $10^{-2}, 10^{-3}$ and $10^{-4}$ dilutions were plated onto Petri dishes containing different media to target the isolation of a wider biodiversity: Tryptic Soy Agar (TSA; BD Difco, Franklin Lakes, NJ, USA), YMA (Laboratorios Microkit, Madrid, Spain), 869 medium (Tryptone $(10 \mathrm{~g} / \mathrm{L})$, yeast extract $(5 \mathrm{~g} / \mathrm{L}), \mathrm{NaCl}(5 \mathrm{~g} / \mathrm{L})$, D-glucose $(1 \mathrm{~g} / \mathrm{L}), \mathrm{CaCl}_{2}(0.345 \mathrm{~g} / \mathrm{L})$, and agar $(20 \mathrm{~g} / \mathrm{L}))$ and ten times diluted 869 medium.

Plates were incubated at $28^{\circ} \mathrm{C}$ for 21 days. The emerging bacterial colonies were regularly isolated to get pure cultures. Their names were composed by CDV or PDA, depending on the sampling origin, followed by BN, from Brassica napus and a correlative number. Then, isolated strains were stored in a sterile $20 \%$ glycerol solution at $-80^{\circ} \mathrm{C}$ for long-term storage.

For bacterial strain identification, DNA was obtained using the REDExtract-N-Amp ${ }^{\mathrm{TM}}$ PCR Ready Mix (Sigma-Aldrich Co. LLC), following the instructions given by the manufacturer. Then, strains were grouped at species or subspecies level based on their 879F-RAPD fingerprints, obtained as detailed by Igual et al. [26] and grouped by means of the UPGMA algorithm (unweighted pair grouping with mathematic average) using the software package BioNumerics version 4.5 (Applied Maths NV, Sint-Martens-Latem, Belgium), with a threshold of $75 \%$ similarity. To identify a representative bacterial isolate of each 879F-RAPD group, 16S rRNA gene sequences were amplified as described in Rivas et al. [27] and processed as described in Poveda et al. [28]. Nearly complete ( 1500 bp) sequences were compared with those from type strains deposited in GenBank using BLASTn program [29] and EzTaxon tool [30].

In the case of those bacterial strains selected for genome sequences, housekeeping gene sequences (gyr $\mathrm{B}$ and $r p o \mathrm{~B}$ ) were retrieved from the genome and compared to those available in the GenBank database using BLASTn for a more accurate taxonomic identification.

In the case of the strain inoculated in the field trials, a phylogenetic analysis of the $16 \mathrm{~S}$ rRNA gene sequence of the strain and those of the closely related species was done as detailed in Jiménez-Gómez et al. [31]. 


\subsection{In Vitro Analyses of Plant Growth-Promoting Mechanisms and Biosynthesis of Polysaccharides}

Bacterial siderophore production and solubilization of non-assimilable phosphates were evaluated as detailed in Jiménez-Gómez et al. [31]. Briefly, siderophore production was evaluated by inoculating in M9-CAS-agar medium plates [32] modified according to the suggestions given by Alexander and Zuberer [33]. The solubilization of non-soluble phosphates into soluble assimilable ions was analyzed in Pikovskaya medium plates [34], which contain bicalcium phosphate $\left(\mathrm{CaHPO}_{4}\right)$ or tricalcium phosphate $\left[\mathrm{Ca}_{3}\left(\mathrm{PO}_{4}\right)_{2}\right]$ as the $\mathrm{P}$ source. Polysaccharide (cellulose and cellulose-like polymers) biosynthesis ability of each isolate was determined as described by Robledo et al. [35]. All plates were incubated for up to 21 days at $28^{\circ} \mathrm{C}$, recording the results every week. Nitrogen fixation was assayed in liquid medium as detailed in Poveda et al. [28]. The method shows the ability of strains to grow in a N-free minimal liquid medium. Indole acetic acid (IAA)-like compound production was measured by the colorimetric method described in Khalid et al. [36].

\subsection{Effects of Bacterial Isolates on Rapeseed Seedlings}

Rapeseed seeds (cv rescator) were surface-disinfected with 70\% ethanol for two min, followed by soaking in an aqueous $5 \%$ sodium hypochlorite solution for ten minutes. Then, they were washed five times with sterile water and pre-germinated on water-agar plates (1.5\%) for $24 \mathrm{~h}$. To prepare the inoculum, bacteria were grown in their respective isolation media for 3 days at $28^{\circ} \mathrm{C}$; afterwards, the Petri dishes were flooded with saline buffer $(0.9 \% \mathrm{NaCl})$ in order to obtain the cell suspensions, which were adjusted to an O.D. ( $600 \mathrm{~nm}$ ) of 0.5 , corresponding to final concentrations of $\sim 10^{8}-10^{9} \mathrm{CFU} / \mathrm{mL}$ (this concentration was determined after counting the number of viable cells using the serial decimal dilution method). After the pre-germination and inoculum preparation steps, Petri dishes containing the seedlings were inoculated. Twelve plates per treatment with five seeds per plate were prepared for the in vitro analyses. Thirty seedlings per treatment were collected at five and fifteen days post-inoculation, respectively. Values of seedling height and root length were recorded at each collection time.

\subsection{Draft Genome Sequencing and Annotation}

The genome sequence was obtained from selected strains after the plant growth promotion tests on rapeseed seedlings. For genome sequencing, the DNA was obtained from selected bacteria after two days of growth at $28^{\circ} \mathrm{C}$ using the Quick DNA Fungal/Bacterial Miniprep kit (Zymo Research, Irvine, CA, USA) following the procedure described by the manufacturer.

The draft genome of selected isolates was sequenced on an Illumina MiSeq platform as described by Saati-Santamaría et al. [37]. The sequence data were assembled using Velvet (v1.12.10) [38]. Gene calling, annotation, and search for genes related to plant growth promotion- and colonization-related capabilities was performed using RAST (v2.0) pipeline [39] and then re-checked by BLASTp against known conserved proteins from phylogenetically related or closest relatives Pseudomonas strains. The Genome Shotgun project for strains CDVBN10 and CDVBN20 has been deposited at DDBJ/EMBL/GenBank under the accessions VDLV00000000 and VDLW00000000, respectively. The versions described in this paper are versions VDLV01000000 and VDLW01000000.

\subsection{Field Experiment}

The most promising PGP bacterium according to in vitro, in vivo, and in silico experiments, strain Pseudomonas brassicacearum CDVBN10, was assayed in field conditions as a rapeseed biofertilizer.

The field trial was performed between September 2018 and May 2019 in the locality of Cañizal (Zamora; NS/EW coordinates: 41.152627/-5.356508). The field has a crop history of rotations between sunflower and barley. No rapeseed crops were sown previously in this soil. The soil is a non-saline soil with loamy-sandy texture, with a good organic matter content $(5.6 \%)$, showing a very slightly basic $\mathrm{pH}(7.87)$ and a low EC (EC1:2 $0.096 \mathrm{dS} / \mathrm{m})$. The electrical conductivity and the $\mathrm{pH}$ were measured according to Dellavalle [40]. The mineral content of the soil is as follows: total $\mathrm{N}<0.045 \%$; assimilable 
$\mathrm{P} 15 \mathrm{mg} / \mathrm{kg}, \mathrm{K} 0.25 \%$, Zn $21.9 \mathrm{mg} / \mathrm{Kg}$, Fe 1.2\%. The number of colony formation units (CFU) per gram of soil (counted in Plate Counting Agar (PCA; Sigma-Aldrich Co. LLC, St. Louis, MO, USA) plates incubated at $28^{\circ} \mathrm{C}$ for 7 days) is $1.2 \times 10^{7}$.

The experimental field was divided in six rows with $5 \mathrm{~m}$ length by $2 \mathrm{~m}$ width $\left(10 \mathrm{~m}^{2}\right)$ with a $0.5 \mathrm{~m}$ buffer non-cropped area between them to avoid the transfer of bacteria between plots. Plants were grown in a density of 12 plants per linear meter in each row and they were rainfed.

The experiment was arranged in a randomized block design with three replicates per treatment. No chemical fertilization was applied to the soil. One month after the seeding, once the seedlings had emerged, a bacterial suspension with a cell density of $10^{9} \mathrm{CFU} / \mathrm{mL}$ was prepared on sterile saline buffer $(0.9 \% \mathrm{NaCl})$, using 3 day old bacterial cultures grown at $28^{\circ} \mathrm{C}$ in TSA. A total of $5 \mathrm{~mL}$ of the bacterial suspension was added to each plant. For uninoculated control, equal volume of sterile saline buffer was added per plant. Fifteen days after the inoculation of the plants, the application was repeated.

The rapeseed plants were collected at seed maturity stage, approximately 8 months after seeding. Thirty randomly selected plants of each plot were harvested and kept separately. Plants were quickly taken to the lab on ice, where we separated roots from shoots carefully. Roots were excised for further amplicon sequencing. From each plant, grain yield and total shoot dry biomass (oven-dried at $60^{\circ} \mathrm{C}$ ) were recorded. Dry plants were also used for the analysis of N, C, Fe, P, K at the Ionomics Service at CEBAS-CSIC (Murcia, Spain), using an Elemental Analyst model TruSpec CN628 equipment (Leco, St Joseph, MI, USA) for the N analysis, and ICP THERMO ICAP 6500DUO equipment (Thermo Fisher, Waltham, MA, USA) for the analysis of the remaining elements.

\subsection{Amplicon Sequencing and Sequence Analysis}

Total genomic DNA was obtained from rapeseed roots collected as explained in the previous section using the DNeasy Power Plant Pro Kit (Qiagen ${ }^{\circledR}$, Venlo, Netherlands), following the instructions given by the manufacturer. For each location, DNA from roots of three different plants of each treatment was pooled and amplicons of the complete bacterial 16S rRNA gene (V1-V9 regions) were sequenced on a PacBio Sequel system using a SMRT Cell 1M V3 LR. PacBio circular consensus sequences (CCS) were used to obtain sequences with a low error rate in the consensus sequence resulting from the alignment between all the subreads from the same molecule.

Sequences with lengths $\geq 800 \mathrm{nt}$ to $\leq 1600 \mathrm{nt}$ were filtered using SEED2 software package [41]. QIIME (v1.9) software [42] was used for amplicon data analysis. The sequences were aligned and taxonomically classified (97\% threshold) using the Greengenes $16 \mathrm{~S}$ rRNA sequence database, release 13.8.97 [43] with an open-reference picking method for the OTU (Operational Taxonomic Units) clustering, using the default settings of the UCLUST algorithm. Chimeric sequences were removed using UCHIME (v6.1.544) [44]. Lineages belonging to chloroplast and mitochondria were removed with QIIME scripts. PacBio reads were deposited in NCBI under the SRA accession PRJNA601164.

Comparison between control and bacteria-treated samples and plots summarizing taxa were made following QIIME scripts. The alpha diversity was measured with the Phylogenetic Diversity (PD), Chao1, Shannon's, Simpson's and Good's coverage indexes. Comparisons between treatments were made using the Kruskal-Wallis statistic test [45] applying the Benjamini-Hochberg false discovery rate (FDR) procedure for multiple comparisons [46]. OTU tables were rarefied using the lower sequence count among all samples as maximum rarefaction depth. The beta diversity of the samples was measured using weighted and unweighted UniFrac distances. Beta diversity comparison of treatments was made through nonparametric $p$-values with the Bonferroni correction [47], calculated after 999 Monte Carlo permutations. A value of $p>0.05$ was used as a threshold for statistical significance of OTU correlation to a control or treated samples.

\subsection{Statistical Analysis of Plant Parameters}

Statistical comparisons of plant growth assays, including parameters recorded of the plants collected from the field assay, were carried out using the StatView 5.0 (SAS Institute, Inc., Cary, 
NC, USA) [48] and performed using one-way analysis of variance (ANOVA). P values of 0.05 or less $(p \leq 0.05)$ were considered statistically significant. Fisher's protected least significant differences (LSD) test was used as post hoc test.

\section{Results}

\subsection{Bacterial Culturome Shows the High Diversity of B. Napus Associated Endophytic Bacteria}

Using a combination of rich and minimal media to target the isolation of a wider biodiversity, we obtained 112 bacterial isolates from surface-disinfected rapeseed roots collected in the same Spanish locations previously mentioned. From them, 31 strains were isolated from plants collected in PDA and 81 from plants collected in CDV (Table 1).

We used 879F-RAPD fingerprints to group the strains at infraspecific level in order to select representative strains for their identification. The 31 strains from the location of PDA (Zamora) clustered into 20 different $879 \mathrm{~F}-\mathrm{RAPD}$ groups, while the 81 bacterial isolates from the locality of CDV (Salamanca) clustered into 56 different groups (Table 1).

Afterwards, we chose a representative strain (marked in Table 1 with an asterisk) from each 879F-RAPD group to obtain its 16S rRNA gene sequence. Then, we compared the obtained sequences with those of the type strains of described species. The closest related species to each isolate is shown in Table 1. The bacterial community analysis of the culturable bacterial endophytes of the rapeseed roots of plant collected in the two agricultural lands of this study revealed the presence of 39 different species within 27 different genera (Table 1 ).

The dominant genera were Pseudomonas, Pseudoarthrobacter and Bacillus, with 49, 12 and 10 strains belonging to 29, 4 and 6 different 879 F-RAPD groups, respectively. In addition, strains belonging to these three genera were found in plants cultivated in both locations of this study, while all the other genera were location specific.

\subsection{In Vitro Analyses of Plant Growth-Promoting Mechanisms}

The in vitro tests of PGP potential include the analyses of phosphorous (P) solubilization, siderophores production and cellulose biosynthesis.

The results of the in vitro analyses of the PGP traits performed in this study are summarized in Table 1. A total of $77.4 \%$ and $67.9 \%$ of the isolates associated with plants from PDA and CDV, respectively, solubilize phosphate. Concerning siderophores, $38.7 \%$ of the strains isolated from PDA showed siderophore production, whereas $55.5 \%$ of the bacterial isolates from CDV produced these iron-chelating molecules. Finally, more than half of the strains from this study showed capability to synthesize cellulose or cellulose-like polymers.

Regarding PGP traits of the bacteria selected for the in planta experiments, all strains but one synthesized IAA-like molecules, all but one solubilized tricalcium phosphate and only Bacillus simplex CDVBN6 was able to grow with no addition of a nitrogen source in the medium.

\subsection{Plant Growth Promotion in Rapeseed Seedlings under Controlled Conditions and Additional PGP Traits}

Those strains showing the best results in the in vitro test of PGP traits (grey-highlighted name in Table 1) were used to evaluate their PGP capability in planta, using rapeseed seedlings. These strains were also assayed for IAA-like production, nitrogen fixation and $\mathrm{Ca}_{3}(\mathrm{PO} 4)_{2}$ solubilization. The results for the PGP ability of these strains are summarized in Table 2. 
Table 1. Identification of strains isolated in this study and in vitro plant growth-promoting mechanisms.

\begin{tabular}{|c|c|c|c|c|c|c|c|c|}
\hline Strain & $\begin{array}{l}\text { Bacterial } \\
\text { Growth } \\
\text { Medium }\end{array}$ & $879 F^{*}$ & $\begin{array}{c}\text { Most Closely Related } \\
\text { Type Strain } \\
\text { Based on the 16S } \\
\text { rRNA Gene }\end{array}$ & $\begin{array}{c}\text { \% Similarity with } \\
\text { the Most Closely } \\
\text { Related Type } \\
\text { Strain (16S rRNA) }\end{array}$ & Taxonomy & Siderophores & Cellulose & P Solub \\
\hline CDVBN92A & $8691 / 10$ & I & $\begin{array}{c}\text { Pseudarthrobacter } \\
\text { oxydans ATCC } 14358^{\mathrm{T}}\end{array}$ & - & $\begin{array}{l}\text { Actinobacteria, } \\
\text { Actinobacteria, } \\
\text { Micrococcales, } \\
\text { Micrococcaceae }\end{array}$ & & & \\
\hline CDVBN98* & $8691 / 10$ & I & $\begin{array}{c}\text { Pseudarthrobacter } \\
\text { oxydans ATCC } 14358^{\mathrm{T}}\end{array}$ & 99.58 & $\begin{array}{c}\text { Actinobacteria, } \\
\text { Actinobacteria, } \\
\text { Micrococcales, } \\
\text { Micrococcaceae }\end{array}$ & & & \\
\hline CDVBN100* & $8691 / 10$ & II & $\begin{array}{l}\text { Isoptericola nanjingensis } \\
\mathrm{H} 17^{\mathrm{T}}\end{array}$ & 97.42 & $\begin{array}{c}\text { Actinobacteria, } \\
\text { Actinobacteria, } \\
\text { Micrococcales, } \\
\text { Promicromonosporaceae }\end{array}$ & & & \\
\hline PDABN24A * & YMA & IV & $\begin{array}{c}\text { Dermacoccus } \\
\text { nishinomiyaensis DSM } \\
20448^{\mathrm{T}}\end{array}$ & 99.35 & $\begin{array}{c}\text { Actinobacteria, } \\
\text { Actinobacteria, } \\
\text { Micrococcales, } \\
\text { Dermacoccaceae } \\
\end{array}$ & & & \\
\hline CDVBN92B * & $8691 / 10$ & $\mathrm{~V}$ & $\begin{array}{l}\text { Agromyces ramosus DSM } \\
43045^{\mathrm{T}}\end{array}$ & 99.45 & $\begin{array}{c}\text { Actinobacteria, } \\
\text { Actinobacteria, } \\
\text { Micrococcales, } \\
\text { Microbacteriaceae }\end{array}$ & & & \\
\hline CDVBN29* & YMA & VI & $\begin{array}{c}\text { Clavibacter capsici LMG } \\
29047^{\mathrm{T}}\end{array}$ & 99.93 & $\begin{array}{c}\text { Actinobacteria, } \\
\text { Actinobacteria, } \\
\text { Micrococcales, } \\
\text { Microbacteriaceae }\end{array}$ & & & \\
\hline CDVBN34 & TSA & VI & $\begin{array}{c}\text { Clavibacter capsici LMG } \\
29047^{\mathrm{T}}\end{array}$ & - & $\begin{array}{c}\text { Actinobacteria, } \\
\text { Actinobacteria, } \\
\text { Micrococcales, } \\
\text { Microbacteriaceae }\end{array}$ & & & \\
\hline CDVBN89* & $8691 / 10$ & VII & $\begin{array}{c}\text { Microbacterium yannicii } \\
\text { DSM } 23203^{\mathrm{T}}\end{array}$ & 98.95 & $\begin{array}{c}\text { Actinobacteria, } \\
\text { Actinobacteria, } \\
\text { Micrococcales, } \\
\text { Microbacteriaceae }\end{array}$ & & & \\
\hline
\end{tabular}


Table 1. Cont

\begin{tabular}{|c|c|c|c|c|c|c|c|c|}
\hline Strain & $\begin{array}{l}\text { Bacterial } \\
\text { Growth } \\
\text { Medium }\end{array}$ & $879 F^{*}$ & $\begin{array}{l}\text { Most Closely Related } \\
\text { Type Strain } \\
\text { Based on the 16S } \\
\text { rRNA Gene }\end{array}$ & $\begin{array}{c}\text { \% Similarity with } \\
\text { the Most Closely } \\
\text { Related Type } \\
\text { Strain (16S rRNA) }\end{array}$ & Taxonomy & Siderophores & Cellulose & P Solub \\
\hline CDVBN50 * & $8691 / 10$ & VIII & $\begin{array}{l}\text { Microbacterium yannicii } \\
\qquad \mathrm{G} 72^{\mathrm{T}}\end{array}$ & 100 & $\begin{array}{c}\text { Actinobacteria, } \\
\text { Actinobacteria, } \\
\text { Micrococcales, } \\
\text { Microbacteriaceae }\end{array}$ & & & \\
\hline CDVBN46A & $8691 / 10$ & IX & $\begin{array}{c}\text { Arthrobacter humícola } \\
\mathrm{KV}^{-653^{\mathrm{T}}}\end{array}$ & - & $\begin{array}{c}\text { Actinobacteria, } \\
\text { Actinobacteria, } \\
\text { Micrococcales, } \\
\text { Micrococcaceae }\end{array}$ & & & \\
\hline CDVBN60* & $8691 / 10$ & IX & $\begin{array}{c}\text { Arthrobacter humícola } \\
\mathrm{KV}^{-653^{\mathrm{T}}}\end{array}$ & 99.71 & $\begin{array}{c}\text { Actinobacteria, } \\
\text { Actinobacteria, } \\
\text { Micrococcales, } \\
\text { Micrococcaceae }\end{array}$ & & & \\
\hline CDVBN84 * & TSA & $x$ & $\begin{array}{l}\text { Arthrobacter pascens } \\
\text { DSM } 20545^{\mathrm{T}}\end{array}$ & 98.73 & $\begin{array}{c}\text { Actinobacteria, } \\
\text { Actinobacteria, } \\
\text { Micrococcales, } \\
\text { Micrococcaceae }\end{array}$ & & & \\
\hline PDABN28* & $8691 / 10$ & XI & $\begin{array}{l}\text { Micrococcus yunnanensis } \\
\text { YIM } 65004^{\mathrm{T}}\end{array}$ & 99.57 & $\begin{array}{c}\text { Actinobacteria, } \\
\text { Actinobacteria, } \\
\text { Micrococcales, } \\
\text { Micrococcaceae }\end{array}$ & & & \\
\hline CDVBN49 * & $8691 / 10$ & XII & $\begin{array}{c}\text { Pseudarthrobacter } \\
\text { oxydans ATCC } 14358^{\mathrm{T}}\end{array}$ & 99.58 & $\begin{array}{c}\text { Actinobacteria, } \\
\text { Actinobacteria, } \\
\text { Micrococcales, } \\
\text { Micrococcaceae }\end{array}$ & & & \\
\hline CDVBN42* & 869 1/10 & XIII & $\begin{array}{c}\text { Pseudarthrobacter } \\
\text { oxydans ATCC } 14358^{\mathrm{T}}\end{array}$ & 99.58 & $\begin{array}{c}\text { Actinobacteria, } \\
\text { Actinobacteria, } \\
\text { Micrococcales, } \\
\text { Micrococcaceae }\end{array}$ & & & \\
\hline CDVBN43 & $8691 / 10$ & XIII & $\begin{array}{c}\text { Pseudarthrobacter } \\
\text { oxydans ATCC } 14358^{\mathrm{T}}\end{array}$ & - & $\begin{array}{c}\text { Actinobacteria, } \\
\text { Actinobacteria, } \\
\text { Micrococcales, } \\
\text { Micrococcaceae }\end{array}$ & & & \\
\hline
\end{tabular}


Table 1. Cont

\begin{tabular}{|c|c|c|c|c|c|c|c|c|}
\hline Strain & $\begin{array}{c}\text { Bacterial } \\
\text { Growth } \\
\text { Medium }\end{array}$ & $879 F^{*}$ & $\begin{array}{l}\text { Most Closely Related } \\
\text { Type Strain } \\
\text { Based on the 16S } \\
\text { rRNA Gene }\end{array}$ & $\begin{array}{c}\text { \% Similarity with } \\
\text { the Most Closely } \\
\text { Related Type } \\
\text { Strain (16S rRNA) }\end{array}$ & Taxonomy & Siderophores & Cellulose & P Solub \\
\hline CDVBN44 & 869 1/10 & XIII & $\begin{array}{c}\text { Pseudarthrobacter } \\
\text { oxydans ATCC } 14358^{\mathrm{T}}\end{array}$ & - & $\begin{array}{c}\text { Actinobacteria, } \\
\text { Actinobacteria, } \\
\text { Micrococcales, } \\
\text { Micrococcaceae }\end{array}$ & & & \\
\hline CDVBN53* & $8691 / 10$ & XIV & $\begin{array}{c}\text { Pseudarthrobacter } \\
\text { oxydans ATCC } 14358^{\mathrm{T}}\end{array}$ & 99.58 & $\begin{array}{c}\text { Actinobacteria, } \\
\text { Actinobacteria, } \\
\text { Micrococcales, } \\
\text { Micrococcaceae }\end{array}$ & & & \\
\hline CDVBN73 & $8691 / 10$ & XIV & $\begin{array}{c}\text { Pseudarthrobacter } \\
\text { oxydans ATCC } 14358^{\mathrm{T}}\end{array}$ & - & $\begin{array}{c}\text { Actinobacteria, } \\
\text { Actinobacteria, } \\
\text { Micrococcales, } \\
\text { Micrococcaceae }\end{array}$ & & & \\
\hline CDVBN57 * & $8691 / 10$ & XV & $\begin{array}{c}\text { Pseudarthrobacter } \\
\text { oxydans ATCC } 14358^{\mathrm{T}}\end{array}$ & 99.58 & $\begin{array}{c}\text { Actinobacteria, } \\
\text { Actinobacteria, } \\
\text { Micrococcales, } \\
\text { Micrococcaceae }\end{array}$ & & & \\
\hline CDVBN61 & $8691 / 10$ & XV & $\begin{array}{c}\text { Pseudarthrobacter } \\
\text { oxydans ATCC } 14358^{\mathrm{T}}\end{array}$ & - & $\begin{array}{c}\text { Actinobacteria, } \\
\text { Actinobacteria, } \\
\text { Micrococcales, } \\
\text { Micrococcaceae }\end{array}$ & & & \\
\hline CDVBN51 * & $8691 / 10$ & XVI & $\begin{array}{c}\text { Pseudarthrobacter } \\
\text { oxydans ATCC } 14358^{\mathrm{T}}\end{array}$ & 99.58 & $\begin{array}{c}\text { Actinobacteria, } \\
\text { Actinobacteria, } \\
\text { Micrococcales, } \\
\text { Micrococcaceae }\end{array}$ & & & \\
\hline CDVBN33* & TSA & XVII & $\begin{array}{c}\text { Pseudarthrobacter } \\
\text { siccitolerans LMG } \\
27359^{\mathrm{T}}\end{array}$ & 99.44 & $\begin{array}{c}\text { Actinobacteria, } \\
\text { Actinobacteria, } \\
\text { Micrococcales, } \\
\text { Micrococcaceae }\end{array}$ & & & \\
\hline CDVBN72* & $8691 / 10$ & XVIII & $\begin{array}{l}\text { Nocardioides cavernae } \\
\text { YIM A } 1136^{\mathrm{T}}\end{array}$ & 99.36 & $\begin{array}{c}\text { Actinobacteria, } \\
\text { Actinobacteria, } \\
\text { Propionibacteriales, } \\
\text { Nocardioidaceae }\end{array}$ & & & \\
\hline
\end{tabular}


Table 1. Cont

\begin{tabular}{|c|c|c|c|c|c|c|c|c|}
\hline Strain & $\begin{array}{l}\text { Bacterial } \\
\text { Growth } \\
\text { Medium }\end{array}$ & $879 F^{*}$ & $\begin{array}{l}\text { Most Closely Related } \\
\text { Type Strain } \\
\text { Based on the 16S } \\
\text { rRNA Gene }\end{array}$ & $\begin{array}{l}\text { \% Similarity with } \\
\text { the Most Closely } \\
\text { Related Type } \\
\text { Strain (16S rRNA) }\end{array}$ & Taxonomy & Siderophores & Cellulose & P Solub \\
\hline CDVBN90 * & 869 1/10 & XIX & $\begin{array}{l}\text { Nocardioides cavernae } \\
\text { YIM A1136 }\end{array}$ & 99.36 & $\begin{array}{l}\text { Actinobacteria, } \\
\text { Actinobacteria, } \\
\text { Propionibacteriales, } \\
\text { Nocardioidaceae }\end{array}$ & & & \\
\hline CDVBN101 & 869 1/10 & XIX & $\begin{array}{l}\text { Nocardioides cavernae } \\
\text { YIM A1136 }\end{array}$ & - & $\begin{array}{l}\text { Actinobacteria, } \\
\text { Actinobacteria, } \\
\text { Propionibacteriales, } \\
\text { Nocardioidaceae }\end{array}$ & & & \\
\hline CDVBN102 * & 869 1/10 & $x X$ & $\begin{array}{l}\text { Micromonospora coxensis } \\
\text { DSM } 45161^{\mathrm{T}}\end{array}$ & 99.86 & $\begin{array}{c}\text { Actinobacteria; } \\
\text { Actinobacteria; } \\
\text { Micromonosporales; } \\
\text { Micromonosporaceae }\end{array}$ & & & \\
\hline PDABN18 * & 869 1/10 & XXI & $\begin{array}{c}\text { Flavobacterium } \\
\text { pectinovorum } \text { DSM6368 }\end{array}$ & 99.09 & $\begin{array}{c}\text { Bacteroidetes, } \\
\text { Bacteroidetes, } \\
\text { Flavobacteriia, } \\
\text { Flavobacteriales, } \\
\text { Flavobacteriaceae }\end{array}$ & & & \\
\hline PDABN27 * & 869 & XXII & $\begin{array}{l}\text { Staphylococcus cohnii } \\
\text { subsp. cohnii ATCC } \\
29974^{\mathrm{T}}\end{array}$ & 100 & $\begin{array}{l}\text { Firmicutes, Bacilli, } \\
\text { Bacillales, } \\
\text { Staphylococcaceae }\end{array}$ & & & \\
\hline CDVBN19* & 869 & XXIII & $\begin{array}{l}\text { Staphylococcus cohnii } \\
\text { subsp. cohnii ATCC } \\
29974^{\mathrm{T}}\end{array}$ & 99.93 & $\begin{array}{l}\text { Firmicutes, Bacilli, } \\
\text { Bacillales, } \\
\text { Staphylococcaceae }\end{array}$ & & & \\
\hline CDVBN54 & 869 1/10 & XXIV & $\begin{array}{c}\text { Bacillus aryabhattai JCM } \\
13839^{\mathrm{T}}\end{array}$ & - & $\begin{array}{c}\text { Firmicutes, Bacilli, } \\
\text { Bacillales, Bacillaceae }\end{array}$ & & & \\
\hline CDVBN55 & 869 1/10 & XXIV & $\begin{array}{c}\text { Bacillus aryabhattai JCM } \\
13839^{\mathrm{T}}\end{array}$ & - & $\begin{array}{c}\text { Firmicutes, Bacilli, } \\
\text { Bacillales, Bacillaceae }\end{array}$ & & & \\
\hline CDVBN58 & $8691 / 10$ & XXIV & $\begin{array}{c}\text { Bacillus aryabhattai JCM } \\
13839^{\mathrm{T}}\end{array}$ & - & $\begin{array}{c}\text { Firmicutes, Bacilli, } \\
\text { Bacillales, Bacillaceae }\end{array}$ & & & \\
\hline CDVBN68 * & YMA & XXIV & $\begin{array}{c}\text { Bacillus aryabhattai JCM } \\
13839^{\mathrm{T}}\end{array}$ & 99.86 & $\begin{array}{c}\text { Firmicutes, Bacilli, } \\
\text { Bacillales, Bacillaceae }\end{array}$ & & & \\
\hline
\end{tabular}


Table 1. Cont

\begin{tabular}{|c|c|c|c|c|c|c|c|c|}
\hline Strain & $\begin{array}{l}\text { Bacterial } \\
\text { Growth } \\
\text { Medium }\end{array}$ & $879 \mathrm{~F} *$ & $\begin{array}{c}\text { Most Closely Related } \\
\text { Type Strain } \\
\text { Based on the 16S } \\
\text { rRNA Gene }\end{array}$ & $\begin{array}{c}\% \text { Similarity with } \\
\text { the Most Closely } \\
\text { Related Type } \\
\text { Strain (16S rRNA) }\end{array}$ & Taxonomy & Siderophores & Cellulose & P Solub \\
\hline CDVBN9* & 869 1/10 & $X X V$ & $\begin{array}{l}\text { Bacillus megaterium } \\
\text { NBRC } 15308^{\mathrm{T}}\end{array}$ & 100 & $\begin{array}{c}\text { Firmicutes, Bacilli, } \\
\text { Bacillales, Bacillaceae }\end{array}$ & & & \\
\hline CDVBN91 * & 869 1/10 & XXVI & $\begin{array}{c}\text { Bacillus niacini IFO } \\
15566^{\mathrm{T}}\end{array}$ & 99.38 & $\begin{array}{c}\text { Firmicutes, Bacilli, } \\
\text { Bacillales, Bacillaceae }\end{array}$ & & & \\
\hline PDABN29* & 869 1/10 & XXVII & Bacillus safensis FO-36B ${ }^{\mathrm{T}}$ & 99.93 & $\begin{array}{c}\text { Firmicutes, Bacilli, } \\
\text { Bacillales, Bacillaceae }\end{array}$ & & & \\
\hline PDABN11 & TSA & XXVIII & $\begin{array}{l}\text { Bacillus siamensis } \\
\text { PD-A10 }\end{array}$ & - & $\begin{array}{c}\text { Firmicutes, Bacilli, } \\
\text { Bacillales, Bacillaceae }\end{array}$ & & & \\
\hline PDABN19B * & TSA & XXVIII & $\begin{array}{l}\text { Bacillus siamensis } \\
\text { PD-A10 } 0^{\mathrm{T}}\end{array}$ & 99.86 & $\begin{array}{c}\text { Firmicutes, Bacilli, } \\
\text { Bacillales, Bacillaceae }\end{array}$ & & & \\
\hline CDVBN6* & 869 & III & $\begin{array}{l}\text { Bacillus simplex LMG } \\
25856^{\mathrm{T}}\end{array}$ & 99.93 & $\begin{array}{c}\text { Firmicutes, Bacilli, } \\
\text { Bacillales, Bacillaceae }\end{array}$ & & & \\
\hline CDVBN18* & 869 & XXIX & $\begin{array}{c}\text { Pseudomonas baetica } \\
\text { A } 390^{\mathrm{T}}\end{array}$ & 99.79 & $\begin{array}{c}\text { Proteobacteria, } \\
\text { Gammaproteobacteria, } \\
\text { Pseudomonadales, } \\
\text { Pseudomonadaceae }\end{array}$ & & & \\
\hline CDVBN66* & YMA & $X X X$ & $\begin{array}{c}\text { Pseudomonas baetica } \\
\text { A } 390^{\mathrm{T}}\end{array}$ & 99.79 & $\begin{array}{c}\text { Proteobacteria, } \\
\text { Gammaproteobacteria, } \\
\text { Pseudomonadales, } \\
\text { Pseudomonadaceae }\end{array}$ & & & \\
\hline CDVBN28* & YMA & XXXI & $\begin{array}{c}\text { Pseudomonas baetica } \\
\mathrm{A} 390^{\mathrm{T}}\end{array}$ & 99.79 & $\begin{array}{c}\text { Proteobacteria, } \\
\text { Gammaproteobacteria, } \\
\text { Pseudomonadales, } \\
\text { Pseudomonadaceae }\end{array}$ & & & \\
\hline CDVBN2 & YMA & XXXII & $\begin{array}{l}\text { Pseudomonas baetica } \\
\mathrm{A} 390^{\mathrm{T}}\end{array}$ & - & $\begin{array}{c}\text { Proteobacteria, } \\
\text { Gammaproteobacteria, } \\
\text { Pseudomonadales, } \\
\text { Pseudomonadaceae }\end{array}$ & & & \\
\hline CDVBN4 * & YMA & XXXII & $\begin{array}{l}\text { Pseudomonas baetica } \\
\text { A } 390^{\mathrm{T}}\end{array}$ & 99.79 & $\begin{array}{c}\text { Proteobacteria, } \\
\text { Gammaproteobacteria, } \\
\text { Pseudomonadales, } \\
\text { Pseudomonadaceae }\end{array}$ & & & \\
\hline
\end{tabular}


Table 1. Cont

\begin{tabular}{|c|c|c|c|c|c|c|c|c|}
\hline Strain & $\begin{array}{c}\text { Bacterial } \\
\text { Growth } \\
\text { Medium }\end{array}$ & $879 F^{*}$ & $\begin{array}{l}\text { Most Closely Related } \\
\text { Type Strain } \\
\text { Based on the 16S } \\
\text { rRNA Gene } \\
\end{array}$ & $\begin{array}{l}\text { \% Similarity with } \\
\text { the Most Closely } \\
\text { Related Type } \\
\text { Strain (16S rRNA) }\end{array}$ & Taxonomy & Siderophores & Cellulose & P Solub \\
\hline CDVBN8* & 869 & XXXIII & $\begin{array}{c}\text { Pseudomonas baetica } \\
\mathrm{A} 390^{\mathrm{T}}\end{array}$ & 99.79 & $\begin{array}{c}\text { Proteobacteria, } \\
\text { Gammaproteobacteria, } \\
\text { Pseudomonadales, } \\
\text { Pseudomonadaceae }\end{array}$ & & & \\
\hline CDVBN41 * & 869 1/10 & XXXIV & $\begin{array}{c}\text { Pseudomonas baetica } \\
\mathrm{A} 390^{\mathrm{T}}\end{array}$ & 99.79 & $\begin{array}{c}\text { Proteobacteria, } \\
\text { Gammaproteobacteria, } \\
\text { Pseudomonadales, } \\
\text { Pseudomonadaceae }\end{array}$ & & & \\
\hline CDVBN45 & 869 1/10 & XXXIV & $\begin{array}{c}\text { Pseudomonas baetica } \\
\mathrm{A} 390^{\mathrm{T}}\end{array}$ & - & $\begin{array}{c}\text { Proteobacteria, } \\
\text { Gammaproteobacteria, } \\
\text { Pseudomonadales, } \\
\text { Pseudomonadaceae }\end{array}$ & & & \\
\hline CDVBN38* & 869 1/10 & XXXV & $\begin{array}{c}\text { Pseudomonas baetica } \\
\mathrm{A} 390^{\mathrm{T}}\end{array}$ & 99.79 & $\begin{array}{c}\text { Proteobacteria, } \\
\text { Gammaproteobacteria, } \\
\text { Pseudomonadales, } \\
\text { Pseudomonadaceae }\end{array}$ & & & \\
\hline CDVBN39 & 869 1/10 & XXXV & $\begin{array}{c}\text { Pseudomonas baetica } \\
\mathrm{A} 390^{\mathrm{T}}\end{array}$ & - & $\begin{array}{c}\text { Proteobacteria, } \\
\text { Gammaproteobacteria, } \\
\text { Pseudomonadales, } \\
\text { Pseudomonadaceae }\end{array}$ & & & \\
\hline CDVBN37 & 869 1/10 & $X X X V$ & $\begin{array}{l}\text { Pseudomonas baetica } \\
\mathrm{A} 390^{\mathrm{T}}\end{array}$ & - & $\begin{array}{c}\text { Proteobacteria, } \\
\text { Gammaproteobacteria, } \\
\text { Pseudomonadales, } \\
\text { Pseudomonadaceae }\end{array}$ & & & \\
\hline CDVBN22* & YMA & XXXVI & $\begin{array}{c}\text { Pseudomonas baetica } \\
{\text { A } 390^{\mathrm{T}}}^{\text {The }}\end{array}$ & 99.79 & $\begin{array}{c}\text { Proteobacteria, } \\
\text { Gammaproteobacteria, } \\
\text { Pseudomonadales, } \\
\text { Pseudomonadaceae }\end{array}$ & & & \\
\hline
\end{tabular}


Table 1. Cont

\begin{tabular}{|c|c|c|c|c|c|c|c|c|}
\hline Strain & $\begin{array}{c}\text { Bacterial } \\
\text { Growth } \\
\text { Medium }\end{array}$ & $879 F^{*}$ & $\begin{array}{c}\text { Most Closely Related } \\
\text { Type Strain } \\
\text { Based on the 16S } \\
\text { rRNA Gene }\end{array}$ & $\begin{array}{c}\% \text { Similarity with } \\
\text { the Most Closely } \\
\text { Related Type } \\
\text { Strain (16S rRNA) }\end{array}$ & Taxonomy & Siderophores & Cellulose & P Solub \\
\hline CDVBN23* & YMA & XXXVII & $\begin{array}{c}\text { Pseudomonas baetica } \\
\mathrm{A} 390^{\mathrm{T}}\end{array}$ & 99.79 & $\begin{array}{c}\text { Proteobacteria, } \\
\text { Gammaproteobacteria, } \\
\text { Pseudomonadales, } \\
\text { Pseudomonadaceae }\end{array}$ & & & \\
\hline CDVBN70 & YMA & XXXVIII & $\begin{array}{c}\text { Pseudomonas baetica } \\
\text { A } 390^{\mathrm{T}}\end{array}$ & - & $\begin{array}{c}\text { Proteobacteria, } \\
\text { Gammaproteobacteria, } \\
\text { Pseudomonadales, } \\
\text { Pseudomonadaceae }\end{array}$ & & & \\
\hline CDVBN71 * & YMA & XXXVIII & $\begin{array}{c}\text { Pseudomonas baetica } \\
\mathrm{A} 390^{\mathrm{T}}\end{array}$ & 99.79 & $\begin{array}{c}\text { Proteobacteria, } \\
\text { Gammaproteobacteria, } \\
\text { Pseudomonadales, } \\
\text { Pseudomonadaceae }\end{array}$ & & & \\
\hline CDVBN13* & TSA & XXXIX & $\begin{array}{c}\text { Pseudomonas } \\
\text { brassicacearum subsp. } \\
\text { brassicacearum DBK } 11^{\mathrm{T}}\end{array}$ & 99.72 & $\begin{array}{c}\text { Proteobacteria, } \\
\text { Gammaproteobacteria, } \\
\text { Pseudomonadales, } \\
\text { Pseudomonadaceae }\end{array}$ & & & \\
\hline CDVBN14 & TSA & XXXIX & $\begin{array}{c}\text { Pseudomonas } \\
\text { brassicacearum subsp. } \\
\text { brassicacearum DBK } 11^{\mathrm{T}}\end{array}$ & - & $\begin{array}{c}\text { Proteobacteria, } \\
\text { Gammaproteobacteria, } \\
\text { Pseudomonadales, } \\
\text { Pseudomonadaceae }\end{array}$ & & & \\
\hline CDVBN62* & YMA & $\mathrm{XL}$ & $\begin{array}{c}\text { Pseudomonas } \\
\text { brassicacearum subsp. } \\
\text { brassicacearum DBK } 11^{\mathrm{T}}\end{array}$ & 99.79 & $\begin{array}{c}\text { Proteobacteria, } \\
\text { Gammaproteobacteria, } \\
\text { Pseudomonadales, } \\
\text { Pseudomonadaceae }\end{array}$ & & & \\
\hline CDVBN47 * & $8691 / 10$ & XLI & $\begin{array}{c}\text { Pseudomonas } \\
\text { brassicacearum subsp. } \\
\text { brassicacearum DBK } 11^{\mathrm{T}}\end{array}$ & 99.79 & $\begin{array}{c}\text { Proteobacteria, } \\
\text { Gammaproteobacteria, } \\
\text { Pseudomonadales, } \\
\text { Pseudomonadaceae }\end{array}$ & & & \\
\hline CDVBN25* & YMA & XLII & $\begin{array}{c}\text { Pseudomonas } \\
\text { brassicacearum subsp. } \\
\text { brassicacearum DBK } 11^{\mathrm{T}}\end{array}$ & 99.79 & $\begin{array}{c}\text { Proteobacteria, } \\
\text { Gammaproteobacteria, } \\
\text { Pseudomonadales, } \\
\text { Pseudomonadaceae }\end{array}$ & & & \\
\hline
\end{tabular}


Table 1. Cont.

\begin{tabular}{|c|c|c|c|c|c|c|c|c|}
\hline Strain & $\begin{array}{l}\text { Bacterial } \\
\text { Growth } \\
\text { Medium }\end{array}$ & $879 F^{*}$ & $\begin{array}{l}\text { Most Closely Related } \\
\text { Type Strain } \\
\text { Based on the 16S } \\
\text { rRNA Gene }\end{array}$ & $\begin{array}{l}\text { \% Similarity with } \\
\text { the Most Closely } \\
\text { Related Type } \\
\text { Strain (16S rRNA) }\end{array}$ & Taxonomy & Siderophores & Cellulose & P Solub \\
\hline CDVBN27 & YMA & XLII & $\begin{array}{c}\text { Pseudomonas } \\
\text { brassicacearum subsp. } \\
\text { brassicacearum DBK } 11^{\mathrm{T}}\end{array}$ & - & $\begin{array}{c}\text { Proteobacteria, } \\
\text { Gammaproteobacteria, } \\
\text { Pseudomonadales, } \\
\text { Pseudomonadaceae }\end{array}$ & & & \\
\hline CDVBN52* & 869 1/10 & XLIII & $\begin{array}{c}\text { Pseudomonas } \\
\text { brassicacearum subsp. } \\
\text { neoaurantiaca ATCC } \\
49054^{\mathrm{T}}\end{array}$ & 99.79 & $\begin{array}{l}\text { Proteobacteria, } \\
\text { Gammaproteobacteria, } \\
\text { Pseudomonadales, } \\
\text { Pseudomonadaceae }\end{array}$ & & & \\
\hline CDVBN64 * & YMA & XLIV & $\begin{array}{c}\text { Pseudomonas } \\
\text { brassicacearum subsp. } \\
\text { neoaurantiaca ATCC } \\
49054^{\mathrm{T}}\end{array}$ & 99.79 & $\begin{array}{c}\text { Proteobacteria, } \\
\text { Gammaproteobacteria, } \\
\text { Pseudomonadales, } \\
\text { Pseudomonadaceae }\end{array}$ & & & \\
\hline CDVBN26* & YMA & XLV & $\begin{array}{c}\text { Pseudomonas } \\
\text { brassicacearum subsp. } \\
\text { neoaurantiaca ATCC } \\
49054^{\mathrm{T}}\end{array}$ & 99.79 & $\begin{array}{c}\text { Proteobacteria, } \\
\text { Gammaproteobacteria, } \\
\text { Pseudomonadales, } \\
\text { Pseudomonadaceae }\end{array}$ & & & \\
\hline CDVBN108 & TSA & XLVI & $\begin{array}{c}\text { Pseudomonas } \\
\text { brassicacearum subsp. } \\
\text { neoaurantiaca ATCC } \\
49054^{\mathrm{T}}\end{array}$ & - & $\begin{array}{c}\text { Proteobacteria, } \\
\text { Gammaproteobacteria, } \\
\text { Pseudomonadales, } \\
\text { Pseudomonadaceae }\end{array}$ & & & \\
\hline CDVBN21* & TSA & XLVI & $\begin{array}{c}\text { Pseudomonas } \\
\text { brassicacearum subsp. } \\
\text { neoaurantiaca ATCC } \\
49054^{\mathrm{T}} \\
\end{array}$ & 99.86 & $\begin{array}{c}\text { Proteobacteria, } \\
\text { Gammaproteobacteria, } \\
\text { Pseudomonadales, } \\
\text { Pseudomonadaceae }\end{array}$ & & & \\
\hline CDVBN10* & 869 & XLVII & $\begin{array}{c}\text { Pseudomonas } \\
\text { brassicacearum subsp. } \\
\text { neoaurantiaca ATCC } \\
49054^{\mathrm{T}}\end{array}$ & 99.86 & $\begin{array}{c}\text { Proteobacteria, } \\
\text { Gammaproteobacteria, } \\
\text { Pseudomonadales, } \\
\text { Pseudomonadaceae }\end{array}$ & & & \\
\hline CDVBN17 & 869 & XLVII & $\begin{array}{c}\text { Pseudomonas } \\
\text { brassicacearum subsp. } \\
\text { neoaurantiaca ATCC } \\
49054^{\mathrm{T}}\end{array}$ & - & $\begin{array}{c}\text { Proteobacteria, } \\
\text { Gammaproteobacteria, } \\
\text { Pseudomonadales, } \\
\text { Pseudomonadaceae }\end{array}$ & & & \\
\hline
\end{tabular}


Table 1. Cont.

\begin{tabular}{|c|c|c|c|c|c|c|c|c|}
\hline Strain & $\begin{array}{c}\text { Bacterial } \\
\text { Growth } \\
\text { Medium }\end{array}$ & $879 F^{*}$ & $\begin{array}{l}\text { Most Closely Related } \\
\text { Type Strain } \\
\text { Based on the 16S } \\
\text { rRNA Gene } \\
\end{array}$ & $\begin{array}{c}\% \text { Similarity with } \\
\text { the Most Closely } \\
\text { Related Type } \\
\text { Strain (16S rRNA) }\end{array}$ & Taxonomy & Siderophores & Cellulose & P Solub \\
\hline CDVBN24 & YMA & XLVII & $\begin{array}{c}\text { Pseudomonas } \\
\text { brassicacearum subsp. } \\
\text { neoaurantiaca ATCC } \\
49054^{\mathrm{T}} \\
\end{array}$ & - & $\begin{array}{l}\text { Proteobacteria, } \\
\text { Gammaproteobacteria, } \\
\text { Pseudomonadales, } \\
\text { Pseudomonadaceae }\end{array}$ & & & \\
\hline CDVBN11 & TSA & XLVII & $\begin{array}{c}\text { Pseudomonas } \\
\text { brassicacearum subsp. } \\
\text { neoaurantiaca ATCC } \\
49054^{\mathrm{T}} \\
\end{array}$ & - & $\begin{array}{l}\text { Proteobacteria, } \\
\text { Gammaproteobacteria, } \\
\text { Pseudomonadales, } \\
\text { Pseudomonadaceae }\end{array}$ & & & \\
\hline CDVBN15 & TSA & XLVII & $\begin{array}{c}\text { Pseudomonas } \\
\text { brassicacearum subsp. } \\
\text { neoaurantiaca ATCC } \\
49054^{\mathrm{T}} \\
\end{array}$ & - & $\begin{array}{c}\text { Proteobacteria, } \\
\text { Gammaproteobacteria, } \\
\text { Pseudomonadales, } \\
\text { Pseudomonadaceae }\end{array}$ & & & \\
\hline CDVBN1 * & YMA & XLVIII & $\begin{array}{c}\text { Pseudomonas } \\
\text { brassicacearum subsp. } \\
\text { neoaurantiaca ATCC } \\
49054^{\mathrm{T}} \\
\end{array}$ & 99.86 & $\begin{array}{c}\text { Proteobacteria, } \\
\text { Gammaproteobacteria, } \\
\text { Pseudomonadales, } \\
\text { Pseudomonadaceae }\end{array}$ & & & \\
\hline CDVBN69* & YMA & XLIX & $\begin{array}{c}\text { Pseudomonas } \\
\text { brassicacearum subsp. } \\
\text { neoaurantiaca ATCC } \\
49054^{\mathrm{T}} \\
\end{array}$ & 99.86 & $\begin{array}{c}\text { Proteobacteria, } \\
\text { Gammaproteobacteria, } \\
\text { Pseudomonadales, } \\
\text { Pseudomonadaceae }\end{array}$ & & & \\
\hline CDVBN65 * & YMA & $\mathrm{L}$ & $\begin{array}{l}\text { Pseudomonas orientalis } \\
\text { CFML96- } 170^{\mathrm{T}}\end{array}$ & 99.86 & $\begin{array}{c}\text { Proteobacteria, } \\
\text { Gammaproteobacteria, } \\
\text { Pseudomonadales, } \\
\text { Pseudomonadaceae }\end{array}$ & & & \\
\hline CDVBN3 * & YMA & LI & $\begin{array}{l}\text { Pseudomonas orientalis } \\
\text { CFML96-170 } 10^{\mathrm{T}}\end{array}$ & 99.65 & $\begin{array}{c}\text { Proteobacteria, } \\
\text { Gammaproteobacteria, } \\
\text { Pseudomonadales, } \\
\text { Pseudomonadaceae }\end{array}$ & & & \\
\hline CDVBN20* & 869 & LII & $\begin{array}{l}\text { Pseudomonas orientalis } \\
\text { CFML96- } 170^{\mathrm{T}}\end{array}$ & 99.79 & $\begin{array}{c}\text { Proteobacteria, } \\
\text { Gammaproteobacteria, } \\
\text { Pseudomonadales, } \\
\text { Pseudomonadaceae }\end{array}$ & & & \\
\hline
\end{tabular}


Table 1. Cont.

\begin{tabular}{|c|c|c|c|c|c|c|c|c|}
\hline Strain & $\begin{array}{l}\text { Bacterial } \\
\text { Growth } \\
\text { Medium }\end{array}$ & $879 F^{*}$ & $\begin{array}{l}\text { Most Closely Related } \\
\text { Type Strain } \\
\text { Based on the 16S } \\
\text { rRNA Gene }\end{array}$ & $\begin{array}{l}\text { \% Similarity with } \\
\text { the Most Closely } \\
\text { Related Type } \\
\text { Strain (16S rRNA) }\end{array}$ & Taxonomy & Siderophores & Cellulose & P Solub \\
\hline PDABN1 * & TSA & LIII & $\begin{array}{c}\text { Pseudomonas poae DSM } \\
14936^{\mathrm{T}}\end{array}$ & 100 & $\begin{array}{c}\text { Proteobacteria, } \\
\text { Gammaproteobacteria, } \\
\text { Pseudomonadales, } \\
\text { Pseudomonadaceae }\end{array}$ & & & \\
\hline PDABN14 * & YMA & LIV & $\begin{array}{c}\text { Pseudomonas poae DSM } \\
14936^{\mathrm{T}}\end{array}$ & 100 & $\begin{array}{c}\text { Proteobacteria, } \\
\text { Gammaproteobacteria, } \\
\text { Pseudomonadales, } \\
\text { Pseudomonadaceae }\end{array}$ & & & \\
\hline PDABN5 * & 869 & $\mathrm{LV}$ & $\begin{array}{c}\text { Pseudomonas } \\
\text { thivervalensis DSM } \\
13194^{\mathrm{T}}\end{array}$ & 99.86 & $\begin{array}{c}\text { Proteobacteria, } \\
\text { Gammaproteobacteria, } \\
\text { Pseudomonadales, } \\
\text { Pseudomonadaceae }\end{array}$ & & & \\
\hline PDABN12 & YMA & LV & $\begin{array}{c}\text { Pseudomonas } \\
\text { thivervalensis DSM } \\
13194^{\mathrm{T}}\end{array}$ & - & $\begin{array}{c}\text { Proteobacteria, } \\
\text { Gammaproteobacteria, } \\
\text { Pseudomonadales, } \\
\text { Pseudomonadaceae }\end{array}$ & & & \\
\hline PDABN3 * & $8691 / 10$ & LVI & $\begin{array}{c}\text { Pseudomonas } \\
\text { thivervalensis DSM } \\
13194^{\mathrm{T}}\end{array}$ & 99.86 & $\begin{array}{c}\text { Proteobacteria, } \\
\text { Gammaproteobacteria, } \\
\text { Pseudomonadales, } \\
\text { Pseudomonadaceae }\end{array}$ & & & \\
\hline PDABN4 & 869 & LVI & $\begin{array}{c}\text { Pseudomonas } \\
\text { thivervalensis DSM } \\
13194^{\mathrm{T}}\end{array}$ & - & $\begin{array}{c}\text { Proteobacteria, } \\
\text { Gammaproteobacteria, } \\
\text { Pseudomonadales, } \\
\text { Pseudomonadaceae }\end{array}$ & & & \\
\hline PDABN6 & YMA & LVI & $\begin{array}{c}\text { Pseudomonas } \\
\text { thivervalensis DSM } \\
13194^{\mathrm{T}}\end{array}$ & - & $\begin{array}{c}\text { Proteobacteria, } \\
\text { Gammaproteobacteria, } \\
\text { Pseudomonadales, } \\
\text { Pseudomonadaceae }\end{array}$ & & & \\
\hline PDABN7 & YMA & LVI & $\begin{array}{c}\text { Pseudomonas } \\
\text { thivervalensis DSM } \\
13194^{\mathrm{T}}\end{array}$ & - & $\begin{array}{c}\text { Proteobacteria, } \\
\text { Gammaproteobacteria, } \\
\text { Pseudomonadales, } \\
\text { Pseudomonadaceae }\end{array}$ & & & \\
\hline
\end{tabular}


Table 1. Cont.

\begin{tabular}{|c|c|c|c|c|c|c|c|c|}
\hline Strain & $\begin{array}{l}\text { Bacterial } \\
\text { Growth } \\
\text { Medium }\end{array}$ & $879 F^{*}$ & $\begin{array}{l}\text { Most Closely Related } \\
\text { Type Strain } \\
\text { Based on the 16S } \\
\text { rRNA Gene }\end{array}$ & $\begin{array}{c}\text { \% Similarity with } \\
\text { the Most Closely } \\
\text { Related Type } \\
\text { Strain (16S rRNA) }\end{array}$ & Taxonomy & Siderophores & Cellulose & P Solub \\
\hline PDABN8 & YMA & LVI & $\begin{array}{c}\text { Pseudomonas } \\
\text { thivervalensis DSM } \\
13194^{\mathrm{T}}\end{array}$ & - & $\begin{array}{c}\text { Proteobacteria, } \\
\text { Gammaproteobacteria, } \\
\text { Pseudomonadales, } \\
\text { Pseudomonadaceae }\end{array}$ & & & \\
\hline PDABN13 & YMA & LVI & $\begin{array}{c}\text { Pseudomonas } \\
\text { thivervalensis DSM } \\
13194^{\mathrm{T}}\end{array}$ & - & $\begin{array}{l}\text { Proteobacteria, } \\
\text { Gammaproteobacteria, } \\
\text { Pseudomonadales, } \\
\text { Pseudomonadaceae }\end{array}$ & & & \\
\hline PDABN15 & YMA & LVI & $\begin{array}{c}\text { Pseudomonas } \\
\text { thivervalensis DSM } \\
13194^{\mathrm{T}}\end{array}$ & - & $\begin{array}{c}\text { Proteobacteria, } \\
\text { Gammaproteobacteria, } \\
\text { Pseudomonadales, } \\
\text { Pseudomonadaceae }\end{array}$ & & & \\
\hline PDABN2 & YMA & LVI & $\begin{array}{c}\text { Pseudomonas } \\
\text { thivervalensis DSM } \\
13194^{\mathrm{T}}\end{array}$ & - & $\begin{array}{c}\text { Proteobacteria, } \\
\text { Gammaproteobacteria, } \\
\text { Pseudomonadales, } \\
\text { Pseudomonadaceae }\end{array}$ & & & \\
\hline CDVBN16* & $8691 / 10$ & LVII & $\begin{array}{c}\text { Pseudomonas } \\
\text { thivervalensis DSM } \\
13194^{\mathrm{T}}\end{array}$ & 99.86 & $\begin{array}{c}\text { Proteobacteria, } \\
\text { Gammaproteobacteria, } \\
\text { Pseudomonadales, } \\
\text { Pseudomonadaceae }\end{array}$ & & & \\
\hline PDABN26* & YMA & LVIII & $\begin{array}{c}\text { Bosea lathyri DSM } \\
26656^{\mathrm{T}}\end{array}$ & 99.22 & $\begin{array}{c}\text { Proteobacteria, } \\
\text { Alphaproteobacteria, } \\
\text { Rhizobiales, } \\
\text { Bradyrhizobiaceae } \\
\end{array}$ & & & \\
\hline CDVBN78* & 869 1/10 & LIX & $\begin{array}{c}\text { Devosia psychrophila } \\
\text { Cr7- }-05^{\mathrm{T}}\end{array}$ & 99.09 & $\begin{array}{c}\text { Proteobacteria, } \\
\text { Alphaproteobacteria, } \\
\text { Rhizobiales, } \\
\text { Hyphomicrobiaceae }\end{array}$ & & & \\
\hline CDVBN77 * & $8691 / 10$ & $\mathrm{LX}$ & $\begin{array}{l}\text { Microvirga aerophila } \\
\text { KACC } 12743^{\mathrm{T}}\end{array}$ & 97.64 & $\begin{array}{c}\text { Proteobacteria, } \\
\text { Alphaproteobacteria, } \\
\text { Rhizobiales, } \\
\text { Methylobacteriaceae }\end{array}$ & & & \\
\hline
\end{tabular}


Table 1. Cont.

\begin{tabular}{|c|c|c|c|c|c|c|c|c|}
\hline Strain & $\begin{array}{c}\text { Bacterial } \\
\text { Growth } \\
\text { Medium }\end{array}$ & $879 F^{*}$ & $\begin{array}{c}\text { Most Closely Related } \\
\text { Type Strain } \\
\text { Based on the 16S } \\
\text { rRNA Gene }\end{array}$ & $\begin{array}{c}\% \text { Similarity with } \\
\text { the Most Closely } \\
\text { Related Type } \\
\text { Strain (16S rRNA) }\end{array}$ & Taxonomy & Siderophores & Cellulose & P Solub \\
\hline PDABN20* & YMA & LXI & $\begin{array}{l}\text { Neorhizobium alkalisoli } \\
\text { CCBAU } 01393^{\mathrm{T}}\end{array}$ & 99.76 & $\begin{array}{c}\text { Proteobacteria, } \\
\text { Alphaproteobacteria, } \\
\text { Rhizobiales, Rhizobiaceae }\end{array}$ & & & \\
\hline PDABN21 & YMA & LXI & $\begin{array}{l}\text { Neorhizobium alkalisoli } \\
\text { CCBAU } 01393^{\mathrm{T}}\end{array}$ & - & $\begin{array}{c}\text { Proteobacteria, } \\
\text { Alphaproteobacteria, } \\
\text { Rhizobiales, Rhizobiaceae }\end{array}$ & & & \\
\hline PDABN21B * & $8691 / 10$ & LXII & $\begin{array}{l}\text { Agrobacterium nepotum } \\
\qquad 39 / 7^{\mathrm{T}}\end{array}$ & 100 & $\begin{array}{c}\text { Proteobacteria, } \\
\text { Alphaproteobacteria, } \\
\text { Rhizobiales, Rhizobiaceae }\end{array}$ & & & \\
\hline PDABN22B * & 869 1/10 & LXIII & $\begin{array}{l}\text { Agrobacterium nepotum } \\
\qquad 39 / 7^{\mathrm{T}}\end{array}$ & 100 & $\begin{array}{c}\text { Proteobacteria, } \\
\text { Alphaproteobacteria, } \\
\text { Rhizobiales, Rhizobiaceae }\end{array}$ & & & \\
\hline PDABN19A * & 869 & LXIV & $\begin{array}{l}\text { Shinella kummerowiae } \\
\text { CCBAU } 25048^{\mathrm{T}}\end{array}$ & 98.53 & $\begin{array}{c}\text { Proteobacteria, } \\
\text { Alphaproteobacteria, } \\
\text { Rhizobiales, Rhizobiaceae }\end{array}$ & & & \\
\hline PDABN23* & 869 1/10 & LXV & $\begin{array}{l}\text { Shinella kummerowiae } \\
\text { CCBAU } 25048^{\mathrm{T}}\end{array}$ & 98.76 & $\begin{array}{c}\text { Proteobacteria, } \\
\text { Alphaproteobacteria, } \\
\text { Rhizobiales, Rhizobiaceae }\end{array}$ & & & \\
\hline PDABN24B & YMA & LXV & $\begin{array}{l}\text { Shinella kummerowiae } \\
\text { CCBAU } 25048^{\mathrm{T}}\end{array}$ & - & $\begin{array}{c}\text { Proteobacteria, } \\
\text { Alphaproteobacteria, } \\
\text { Rhizobiales, Rhizobiaceae }\end{array}$ & & & \\
\hline PDABN32 * & TSA & LXVI & $\begin{array}{l}\text { Shinella kummerowiae } \\
\text { CCBAU } 25048^{\mathrm{T}}\end{array}$ & 99.76 & $\begin{array}{c}\text { Proteobacteria, } \\
\text { Alphaproteobacteria, } \\
\text { Rhizobiales, Rhizobiaceae }\end{array}$ & & & \\
\hline PDABN23A * & TSA & LXVII & $\begin{array}{l}\text { Shinella kummerowiae } \\
\text { CCBAU } 25048^{\mathrm{T}}\end{array}$ & 99.76 & $\begin{array}{c}\text { Proteobacteria, } \\
\text { Alphaproteobacteria, } \\
\text { Rhizobiales, Rhizobiaceae }\end{array}$ & & & \\
\hline CDVBN83* & YMA & LXVIII & $\begin{array}{c}\text { Sphingomonas faeni DSM } \\
\qquad 14747^{\mathrm{T}}\end{array}$ & 99.78 & $\begin{array}{c}\text { Proteobacteria, } \\
\text { Alphaproteobacteria, } \\
\text { Sphingomonadales, } \\
\text { Sphingomonadaceae }\end{array}$ & & & \\
\hline
\end{tabular}


Table 1. Cont

\begin{tabular}{|c|c|c|c|c|c|c|c|c|}
\hline Strain & $\begin{array}{l}\text { Bacterial } \\
\text { Growth } \\
\text { Medium }\end{array}$ & $879 F^{*}$ & $\begin{array}{l}\text { Most Closely Related } \\
\text { Type Strain } \\
\text { Based on the 16S } \\
\text { rRNA Gene }\end{array}$ & $\begin{array}{l}\text { \% Similarity with } \\
\text { the Most Closely } \\
\text { Related Type } \\
\text { Strain (16S rRNA) }\end{array}$ & Taxonomy & Siderophores & Cellulose & P Solub \\
\hline CDVBN46B * & $8691 / 10$ & LXIX & $\begin{array}{l}\text { Massilia suwonensis } \\
5414 \mathrm{~S}-25^{\mathrm{T}}\end{array}$ & 99.01 & $\begin{array}{c}\text { Proteobacteria, } \\
\text { Betaproteobacteria, } \\
\text { Burkholderiales, } \\
\text { Oxalobacteraceae }\end{array}$ & & & \\
\hline CDVBN40* & $8691 / 10$ & LXX & $\begin{array}{c}\text { Massilia yuzhufengensis } \\
\text { ZD1-4 }\end{array}$ & 98.59 & $\begin{array}{l}\text { Proteobacteria, } \\
\text { Betaproteobacteria, } \\
\text { Burkholderiales, } \\
\text { Oxalobacteraceae }\end{array}$ & & & \\
\hline PDABN9 * & YMA & LXXI & Acidovorax radicis $\mathrm{N} 35^{\mathrm{T}}$ & 99.65 & $\begin{array}{c}\text { Proteobacteria, } \\
\text { Betaproteobacteria, } \\
\text { Burkholderiales, } \\
\text { Comamonadaceae }\end{array}$ & & & \\
\hline CDVBN31 * & TSA & LXXII & $\begin{array}{l}\text { Variovorax paradoxus } \\
\text { NBRC } 15149^{\mathrm{T}}\end{array}$ & 99.52 & $\begin{array}{c}\text { Proteobacteria, } \\
\text { Betaproteobacteria, } \\
\text { Burkholderiales, } \\
\text { Comamonadaceae }\end{array}$ & & & \\
\hline CDVBN59* & $8691 / 10$ & LXXIII & $\begin{array}{l}\text { Herbaspirillum lusitanum } \\
\text { LMG } 21710^{\mathrm{T}}\end{array}$ & 100 & $\begin{array}{l}\text { Proteobacteria, } \\
\text { Betaproteobacteria, } \\
\text { Burkholderiales, } \\
\text { Oxalobacteraceae }\end{array}$ & & & \\
\hline CDVBN63 & YMA & LXXIII & $\begin{array}{l}\text { Herbaspirillum lusitanum } \\
\text { LMG } 21710^{\mathrm{T}}\end{array}$ & - & $\begin{array}{l}\text { Proteobacteria, } \\
\text { Betaproteobacteria, } \\
\text { Burkholderiales, } \\
\text { Oxalobacteraceae }\end{array}$ & & & \\
\hline CDVBN67 & YMA & LXXIII & $\begin{array}{l}\text { Herbaspirillum lusitanum } \\
\text { LMG } 21710^{\mathrm{T}}\end{array}$ & - & $\begin{array}{l}\text { Proteobacteria, } \\
\text { Betaproteobacteria, } \\
\text { Burkholderiales, } \\
\text { Oxalobacteraceae }\end{array}$ & & & \\
\hline CDVBN32* & TSA & LXXIV & $\begin{array}{l}\text { Herbaspirillum lusitanum } \\
\text { LMG } 21710^{\mathrm{T}}\end{array}$ & 99.45 & $\begin{array}{l}\text { Proteobacteria, } \\
\text { Betaproteobacteria, } \\
\text { Burkholderiales, } \\
\text { Oxalobacteraceae }\end{array}$ & & & \\
\hline
\end{tabular}


Table 1. Cont

\begin{tabular}{|c|c|c|c|c|c|c|c|c|}
\hline Strain & $\begin{array}{l}\text { Bacterial } \\
\text { Growth } \\
\text { Medium }\end{array}$ & $879 F^{*}$ & $\begin{array}{l}\text { Most Closely Related } \\
\text { Type Strain } \\
\text { Based on the 16S } \\
\text { rRNA Gene }\end{array}$ & $\begin{array}{l}\text { \% Similarity with } \\
\text { the Most Closely } \\
\text { Related Type } \\
\text { Strain (16S rRNA) }\end{array}$ & Taxonomy & Siderophores & Cellulose & P Solub \\
\hline PDABN25 * & YMA & LXXV & $\begin{array}{c}\text { Shigella flexneri ATCC } \\
29903^{\mathrm{T}}\end{array}$ & 99.58 & $\begin{array}{c}\text { Proteobacteria, } \\
\text { Gammaproteobacteria, } \\
\text { Enterobacterales, } \\
\text { Enterobacteriaceae }\end{array}$ & & & \\
\hline CDVBN81* & TSA & LXXVI & $\begin{array}{l}\text { Acinetobacter johnsonii } \\
\text { ATCC } 17909^{\mathrm{T}}\end{array}$ & 99.51 & $\begin{array}{c}\text { Proteobacteria, } \\
\text { Gammaproteobacteria, } \\
\text { Pseudomonadales, } \\
\text { Moraxellaceae }\end{array}$ & & & \\
\hline
\end{tabular}

Representative strains from each of the 879F groups are marked with asterisks. Grey-highlighted names represent best performing strains regarding the PGP traits. CDV: Castellanos de Villiquera (Salamanca); PDA: Peleas de Arriba (Zamora). Color scale: Grey color means no growth. White color means negative result (growth but no activity). Different shades of blue mean a range from weak (light blue) to strong (dark blue) 
Table 2. Results of plant growth-promoting (PGP) tests (IAA-like compounds, solubilization of bi- and tricalcium phosphate, nitrogen fixation, siderophore and cellulose production) performed with strains selected in the plant promotion assay. All the tests were performed in triplicate.

\begin{tabular}{|c|c|c|c|c|c|c|}
\hline Strain & $\begin{array}{l}\text { IAA-like } \\
\text { Molecules } \\
\left(\mu \mathrm{g} \cdot \mathrm{mL}^{-1}\right)\end{array}$ & $\begin{array}{l}\text { P Solubilization } \\
\qquad\left(\mathrm{Ca}_{3}\left(\mathrm{PO}_{4}\right)_{2}\right)\end{array}$ & N Fixation & Siderophores & Cellulose & $\begin{array}{l}\text { P Solubilization } \\
\left(\mathrm{CaHPO}_{4}\right)\end{array}$ \\
\hline CDVBN4 & 24.53 & + & - & +++ & ++ & +++ \\
\hline CDVBN6 & 5.34 & - & + & +++ & ++ & +++ \\
\hline CDVBN10* & 8.18 & + & - & +++ & ++ & +++ \\
\hline CDVBN20* & 75.19 & $\mathrm{w}$ & - & +++ & + & +++ \\
\hline CDVBN21 & 13.72 & + & - & +++ & ++ & +++ \\
\hline CDVBN65 & 5.14 & + & - & +++ & - & +++ \\
\hline CDVBN68 & 10.07 & + & - & +++ & ++ & +++ \\
\hline CDVBN69 & 8.45 & + & - & +++ & + & +++ \\
\hline CDVBN70 & 0.00 & + & - & +++ & ++ & ++ \\
\hline
\end{tabular}

The results of root and plant height at 5 and 15 days post inoculation (dpi) are shown in Figure 1. The best six bacterial strains according to these results from the 5 dpi samples were re-tested in planta, allowing the seedlings to grow to $15 \mathrm{dpi}$. All six strains but one significantly increased shoot length compared to the uninoculated control (Figure 1).
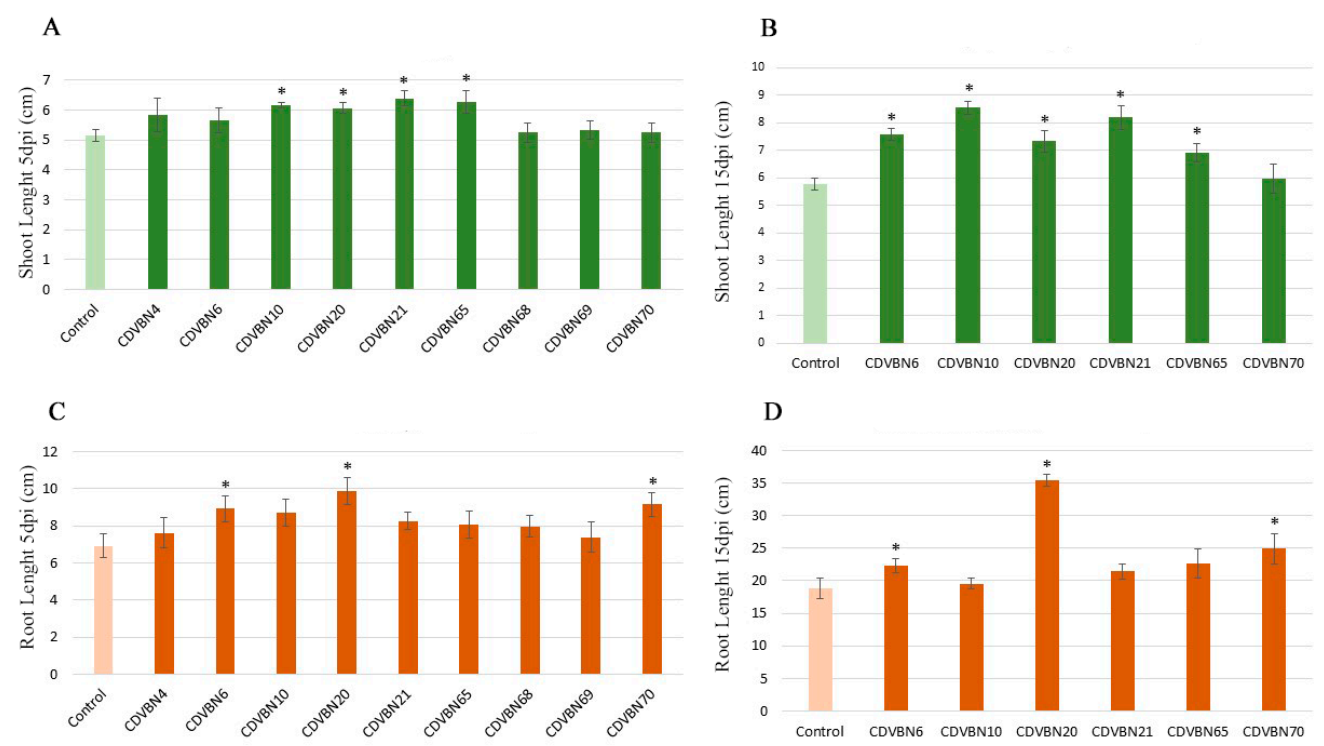

Figure 1. Growth promotion in rapeseed seedlings 5 and 15 days post inoculation (dpi): (A) plant height $5 \mathrm{dpi}$; (B) plant height $15 \mathrm{dpi}$; (C) root length $5 \mathrm{dpi}$; (D) root length $15 \mathrm{dpi}$. Bars indicate the standard error. Histogram bars marked with an asterisk indicate a value significantly different from the negative control $(p=0.05)$ according to Fisher's Protected LSD (Least Significant Differences).

Then, we selected Pseudomonas brassicacearum CDVBN10 and P. orientalis CDVBN20 to obtain their genome sequence and deepen the in silico study of their PGP capabilities. The reasons for the selection of these two strains are the following: (i) they presented good plant growth-promoting traits according to the in vitro assays, (ii) they presented a capability to promote plant growth at 5 and $15 \mathrm{dpi}$, and (iii) they belong to the genus Pseudomonas, the most abundant genus in plants from both locations, which might be related to a positive role of bacteria of this genus within their host plant (see discussion section). 
3.4. Taxonomic Affiliation of the Best Performing Strains

General characteristics of strains CDVBN10 and CDVBN20 genomes are detailed in Table 3, as well as data from Subsystems Categories retrieved from the SeedViewer are shown in Table 4.

Table 3. General genome properties of the PGP strains CDVBN10 and CDVBN20.

\begin{tabular}{lcc}
\hline \multicolumn{1}{c}{ Attributes } & CDVBN10 & CDVBN20 \\
\hline Genome size (bp) & $6,180,897$ & $5,666,760$ \\
GC Content (\%) & 60.8 & 60.6 \\
N50 value & 128,213 & 49,053 \\
L50 value & 15 & 34 \\
Number of contigs (with PEGs) & 85 & 271 \\
Number of subsystems & 403 & 393 \\
Number of coding sequences & 5773 & 5199 \\
Number of RNAs & 61 & 37 \\
\hline
\end{tabular}

Table 4. Number of genes associated with specific functional categories in strains CDVBN10 and CDVBN20.

\begin{tabular}{lcc}
\hline Number of Genes Related to: & CDVBN10 & CDVBN20 \\
\hline Cofactors, vitamins, prosthetic & 219 & 232 \\
groups, pigments & 49 & 49 \\
Cell wall and capsule & 58 & 60 \\
Virulence, disease and defense & 11 & 9 \\
Potassium metabolism & 37 & 39 \\
Miscellaneous & 8 & 3 \\
Phages, prophages, & & \\
transposable elements, & & \\
plasmids & 194 & 151 \\
Membrane transport & 19 & 52 \\
Iron acquisition and & & \\
metabolism & 50 & 52 \\
RNA metabolism & 96 & 101 \\
Nucleosides and nucleotides & 230 & 212 \\
Protein metabolism & 68 & 74 \\
Motility and Chemotaxis & 55 & 61 \\
Regulation and cell signalling & 4 & 4 \\
Secondary metabolism & 101 & 95 \\
DNA metabolism & 155 & 138 \\
Fatty acids, lipids and & & \\
isoprenoids & 55 & 19 \\
Nitrogen metabolism & 4 & 1 \\
Dormancy and sporulation & 133 & 111 \\
Respiration & 106 & 102 \\
Stress response & 94 & 71 \\
Metabolism of aromatic & 548 & 49 \\
compounds & 24 & 261 \\
Amino acids and derivatives & 316 & \\
Sulfur metabolism & & \\
Phosphorus metabolism & & \\
Carbohydrates & & \\
\hline & & \\
& & \\
& & \\
\hline
\end{tabular}

According to the $16 \mathrm{~S}$ rRNA gene sequence, the most closely related type strains to CDVBN10 are P. brassicacearum subsp. neurantiaca CIP109457 ${ }^{\mathrm{T}}(99.79 \%)$, Pseudomonas corrugata DSM7228 ${ }^{\mathrm{T}}(99.65 \%)$ and P. brassicacearum subsp. brassicacearum $\mathrm{DBK} 11^{\mathrm{T}}(99.59 \%)$. The gyrB gene sequence of strain CDVBN10 presented similarities of $94.99 \%, 92.92 \%$, and $94.71 \%$ with those strains, respectively. In the case of the sequence of the rpoB gene, the similarities between the strain CDVBN10 and its closest 
related species were respectively $97.59 \%, 95.28 \%$, and $97.00 \%$. Thus, we can conclude that the most closely related type strain of CDVBN10 is $P$. brassicacearum subsp. neurantiaca CIP109457 ${ }^{\mathrm{T}}$.

The comparison of the $16 \mathrm{~S}$ rRNA gene sequence of strain CDVBN20 with the type strains available in databases showed that its most closely related type strains are P. orientalis CFML97-170 $(99.66 \%)$, Pseudomonas antarctica CMS35 ${ }^{\mathrm{T}}(99.31 \%)$, and Pseudomonas meridiana CMS38 ${ }^{\mathrm{T}}(99.25 \%)$. In the case of the gyrB gene sequence, strain CDVBN20 showed the following similarities with the closest related type strain: $92.48 \%, 90.73 \%$, and $90.73 \%$, respectively. In the case of the sequence of the rpoB gene, the type strains of the most closely related species were not available in the databases. Therefore, according to the $16 \mathrm{~S}$ rRNA and gyrB gene sequences, the most closely related type strain is P. orientalis CFML97-170 ${ }^{\mathrm{T}}$.

\subsection{Genome in Silico Analysis of Plant Growth-Promoting and Putative Colonization Related Mechanisms}

The in silico analyses of the PGP mechanisms of strains CDVBN10 and CDVBN20 showed the presence of genes implicated in several interesting PGP pathways. Both genomes contain genes encoding enzymes involved in the solubilization of inorganic $\mathrm{P}$ or in the release of $\mathrm{P}$ from other molecules, such as exopolyphosphatases (EC 3.6.1.11), polyphosphate kinases (EC 2.7.4.1), inorganic triphosphatases (EC 3.6.1.25), inorganic pyrophosphatases (EC 3.6.1.1), pyrroloquinoline quinones (PQQ), glucose dehydrogenase PQQ-dependent (EC 1.1.5.2) and gluconate 2-dehydrogenase (EC 1.1.99.3), as well as genes of the Pst system (pstSCAB), which is the most conserved member of the Pho regulon [49], and some other genes related to unspecific uptake of this element [24].

Moreover, we found that both bacteria have genes involved in the metabolism of several acids that could solubilize both $\mathrm{K}$ and $\mathrm{P}$, such as the genes encoding citrate synthase (EC 2.3.3.1) and malate synthase G (EC 2.3.3.9) responsible for the synthesis of citric acid and malic acid, respectively, genes related with the metabolism of malonic acid (malonate decarboxylase, malonate utilization transcriptional regulator, malonate-semialdehyde dehydrogenase), of gluconic acid (gluconate 2-dehydrogenase (EC 1.1.99.3), of 2-ketogluconic acid (2-ketogluconate kinase (EC 2.7.1.13), 2-ketogluconate transporter) and of lactic acid (D-lactate dehydrogenase, L-lactate dehydrogenase, L-lactate permease). We also found several genes implicated in $\mathrm{K}$ transport belonging to the Kup and Kef systems [50].

Regarding iron provision, we found a great number of genes linked with Fe uptake, metabolism and Fe efflux systems, as well as the ones related to the production of pyoverdine, a common siderophore in fluorescent $P$ seudomonas [51]. Regarding IAA, one of the main phytohormones responsible of many plant functions and directly related to plant growth, we found that both genomes have genes encoding for some enzymes related to IAA synthesis, such as the indole-3-glycerol phosphate synthase (EC 4.1.1.48) or the tryptophan synthase (alpha and beta chain; EC 4.2.1.20), amongst others. Nevertheless, we could not find a complete or clear pathway for the biosynthesis of IAA. In addition, using BLASTp search, we found genes encoding 1-aminocyclopropane-1-carboxylic acid (ACC) deaminase activity in both bacteria, an enzyme which catalyzes the conversion of ACC into ammonia and $\alpha$-ketobutyrate, avoiding high levels of ethylene synthesis during abiotic stress situations.

Finally, both genomes showed genes involved in lipopolysaccharide (LPS) biosynthesis, such as $i p x$, waa, $k d t$, ept and gmh genes, or genes related to the LPS-assembly, such as $l p t D$ and lptE. Moreover, genes encoding enzymes involved in the synthesis of exopolysaccharides, such as a cyclic $\beta$-1,2-glucan synthetase, are in both genomes and exo genes, only in the strain CDVBN10. Both genomes also contained genes encoding glycosyl transferases and glycosyl hydrolases, enzymes involved in polysaccharide biosynthesis and biodegradation, and genes encoding transcriptional factors from AraC family. 
3.6. Pseudomonas brassicacearum CDVBN10 Displays Beneficial Effects in Rapeseed Plants Cultivated in the Field

According to in vitro, in silico, and in vivo laboratory experiments, Pseudomonas brassicacearum CDVBN10 and P. orientalis CDVBN20 were shown to be promising plant growth-promoting bacteria. However, and taking into account that $P$. brassicacearum species had been isolated as a root endophyte from several different plants and that the preliminary hypothesis of this study was that bacteria with a good capability to enter plant roots will be more efficient under field conditions, we chose the bacterium P. brassicacearum CDVBN10 to tests its capability to promote plant growth in field conditions (a neighbor-joining phylogenetic tree based on the 16S sequence of the strain CDVBN10 and the closest related species of the genus Pseudomonas is available in the Supplementary Figure S2). Data from field experiments (Figures 2 and 3) showed a significant increase in both seed weight and shoot biomass in those plants inoculated with P. brassicacearum CDVBN10 compared to uninoculated plants. The percentages of the increase in pod number, pod dry weight and shoot dry weight in inoculated plants over the control plants were $216.0 \%, 174.3 \%$, and $197.8 \%$, respectively. Regarding the nutritional content of the plants, inoculated rapeseed plants present a significantly higher content in N, C and K, whereas uninoculated plants presented higher Fe content than those inoculated with P. brassicacearum CDVBN10 (Table 5).

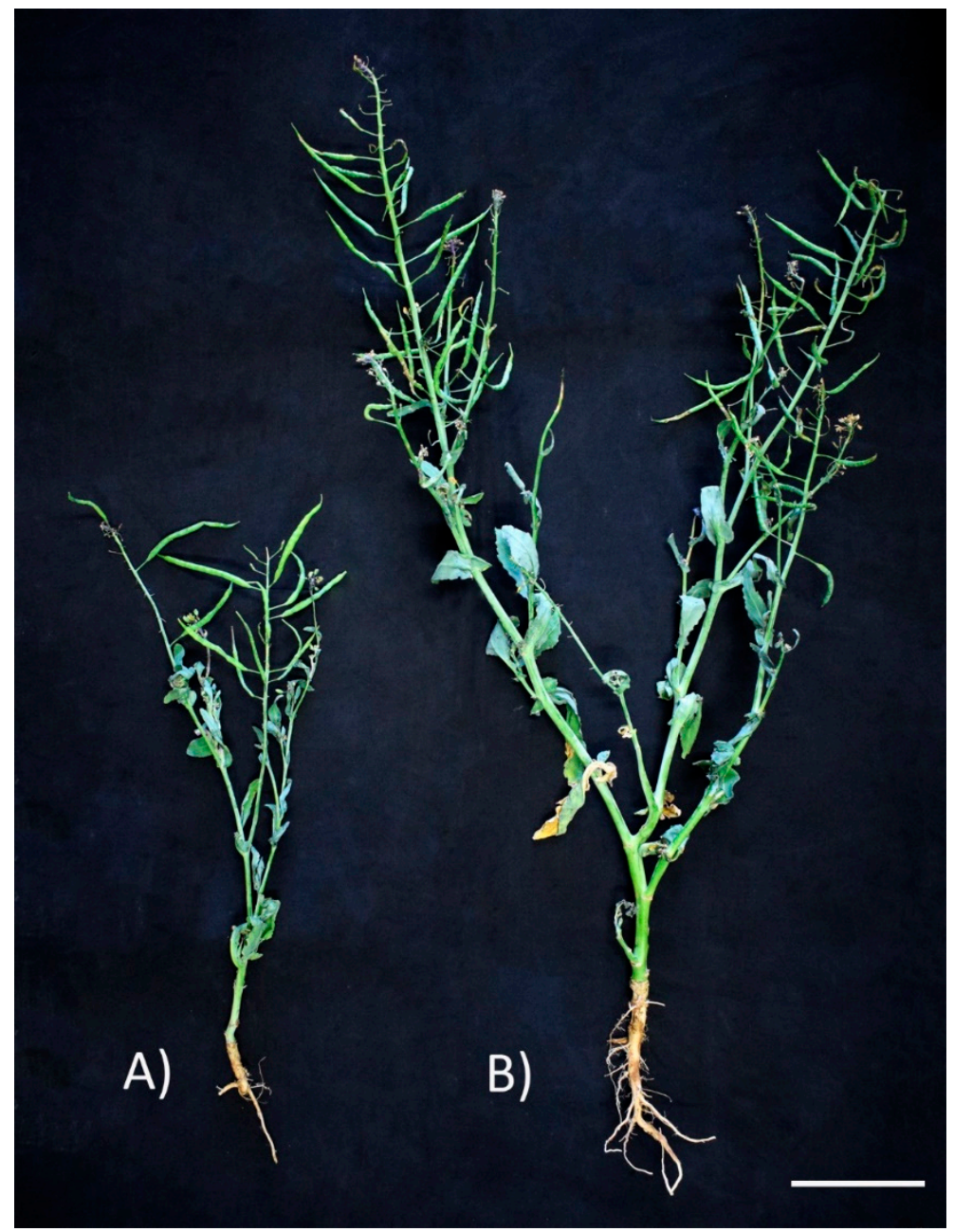

Figure 2. Example of plant growth-promoting effect of P. brassicacearum CDVBN10 on Brassica napus plant in field experiment; (A) control not inoculated, (B) plant inoculated with P. brassicacearum CDVBN10. Bar represents $12 \mathrm{~cm}$. 
(A)

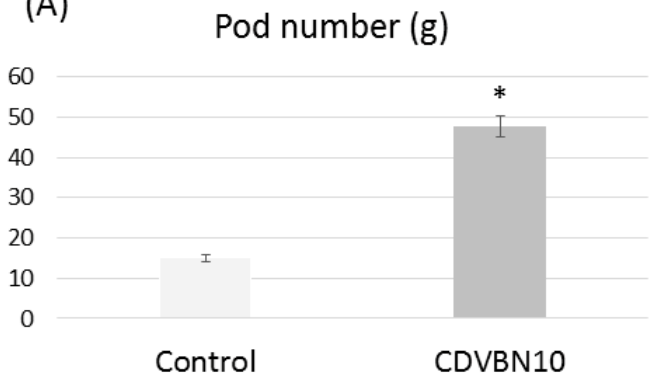

(B)

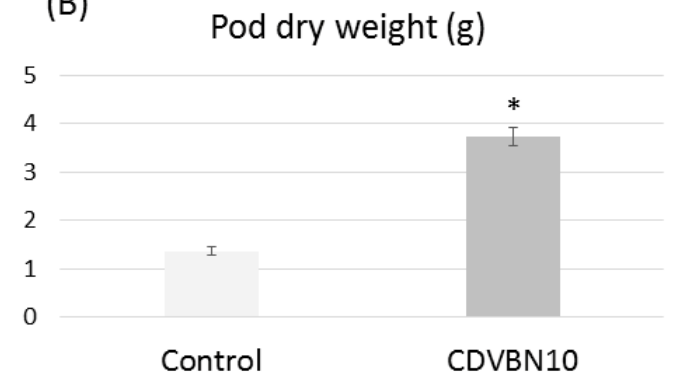

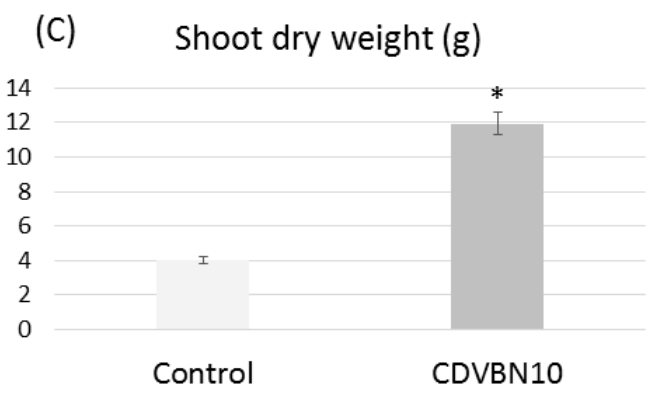

Figure 3. Results of field experiment. (A) Pod number, (B) pod dry weight (g), (C) shoot dry weight $(\mathrm{g})$. Bars indicate the standard error. Histogram bars marked with an asterisk indicate a value significantly different from the negative control $(p=0.01)$ according to Fisher's protected least significant differences (LSD).

Table 5. Effects of Pseudomonas brassicacearum CDVBN10 inoculation on nutrient contents of rapeseed plants grown in the field experiment. Values marked with an asterisk indicate a value significantly different from the negative control $(p=0.05)$ according to Fisher's protected least significant differences (LSD).

\begin{tabular}{cccccc}
\hline Treatment & $\mathbf{N}(\mathrm{g} / \mathbf{1 0 0 g})$ & $\mathbf{C}(\mathrm{g} / \mathbf{1 0 0 g})$ & $\mathbf{F e}(\mathbf{m g} / \mathbf{k g})$ & $\mathbf{K}(\mathrm{g} / \mathbf{1 0 0 g})$ & $\mathbf{P}(\mathrm{g} / \mathbf{1 0 0 g})$ \\
\hline Control & $3.56 \pm 0.05$ & $53.69 \pm 0.49$ & $67.34 \pm 2.52$ & $1.04 \pm 0.01$ & $0.58 \pm 0.02$ \\
\hline CDVBN10 & $3.82 \pm 0.07 *$ & $54.89 \pm 0.19 *$ & $59.60 \pm 1.50 *$ & $0.99 \pm 0.03$ & $0.65 \pm 0.03 *$ \\
\hline
\end{tabular}

3.7. CDVBN10 Inoculation Does Not Significantly Alter Bacterial Diversity in Rapeseed Roots Grown in the Field Trial

The SMRT PacBio sequencing produced a total of 376,370 reads for the eight samples (four uninoculated and four CDVBN10 inoculated). After the filtering, we obtained a total of 96,105 valid reads ( $\geq 800$ and $\leq 1600 \mathrm{bp}$ ), The minimum number of reads per sample was 2381 and the maximum was 21,274 . We performed a clustering based on a threshold of $97 \%$ similarity and assigned taxonomic rank to generate a total of 3419 OTUs (Table 6). Underrepresented OTUs $(n \leq 2)$ were also removed, being a final amount of 2130 OTUs in total.

Setting a level of similarity of $97 \%$ as the threshold and removing singletons and doubletons, the average number of OTUs among the samples was $552.2( \pm 56.81)$ and $541.2( \pm 120.73)$ for CDVBN10-inoculated and uninoculated treatments, respectively. The rarefaction curves for each sample (Figure S1) together with the different alpha diversity indexes (Table 6) show that the most common OTUs are present in the sequencing data. Both alpha (Table 6; Figure 4) and beta diversity (Supplementary Table S1; Figure 5) analyses revealed that there are no statistically significant differences among and within all samples from both treatments and that there are not associations between taxa and treatments (Supplementary Table S2). 
Table 6. Number of sequences, OTUs and alpha diversity indexes of bacterial communities present in the 8 samples, 4 from uninoculated and 4 from CDVBN10-inoculated treatments. No significative differences were found $(p>0.05)$.

\begin{tabular}{|c|c|c|c|c|c|c|c|c|c|}
\hline \multicolumn{2}{|c|}{ Samples } & \multirow{2}{*}{$\begin{array}{c}\begin{array}{c}\text { Raw } \\
\text { Reads }\end{array} \\
40297 \\
\end{array}$} & \multirow{2}{*}{$\begin{array}{c}\begin{array}{c}\text { Reads after } \\
\text { Processing * }\end{array} \\
15884\end{array}$} & \multirow{2}{*}{$\begin{array}{c}\text { Observed } \\
\text { OTUs }\end{array}$} & \multirow{2}{*}{ 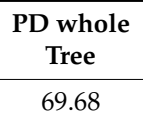 } & \multirow{2}{*}{$\begin{array}{l}\text { Chao-1 } \\
2465.58\end{array}$} & \multirow{2}{*}{$\begin{array}{c}\text { Shannon } \\
5.56\end{array}$} & \multirow{2}{*}{$\begin{array}{c}\text { Simpson } \\
0.75\end{array}$} & \multirow{2}{*}{$\begin{array}{c}\begin{array}{c}\text { Good's } \\
\text { Coverage }\end{array} \\
0.95\end{array}$} \\
\hline CDVBN10 & A1 & & & & & & & & \\
\hline & A2 & 49926 & 15190 & 714 & 71.17 & 2416.30 & 8.35 & 0.97 & 0.96 \\
\hline & A3 & 50086 & 7353 & 537 & 44.89 & 1369.97 & 7.46 & 0.97 & 0.95 \\
\hline & A4 & 30213 & 14870 & 373 & 53.98 & 2083.64 & 3.95 & 0.61 & 0.96 \\
\hline \multirow[t]{4}{*}{ Uninoculated } & B1 & 47285 & 2381 & 532 & 31.42 & 782.39 & 7.51 & 0.97 & 0.90 \\
\hline & B2 & 61430 & 4491 & 525 & 35.55 & 1041.56 & 7.86 & 0.99 & 0.93 \\
\hline & B3 & 44494 & 14480 & 501 & 64.73 & 2201.01 & 5.51 & 0.77 & 0.95 \\
\hline & B4 & 52639 & 21274 & 648 & 81.05 & 2083.64 & 7.48 & 0.94 & 0.96 \\
\hline Total & & 376370 & 96105 & & & & & & \\
\hline
\end{tabular}

\section{A}

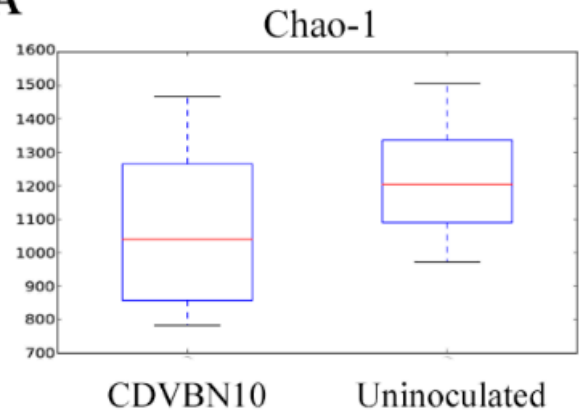

\section{B}

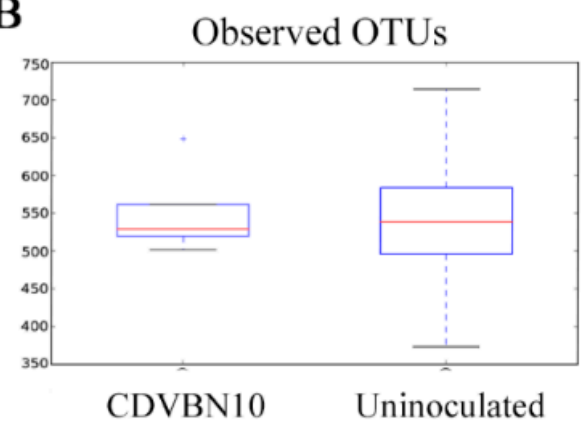

C

PD whole tree

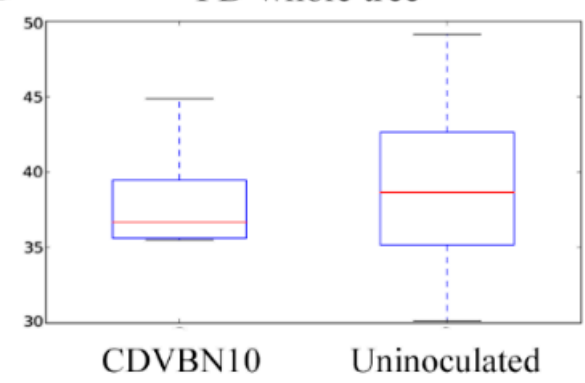

Figure 4. Comparison of alpha diversity between sampling sites; (A) boxplots represent Chao-1 index; (B) OTU richness/observed OTUs; (C) Phylogenetic Diversity (PD) whole tree index. T test was used to detect differences between treatments. No significant differences were found $(p>0.05)$. 
A

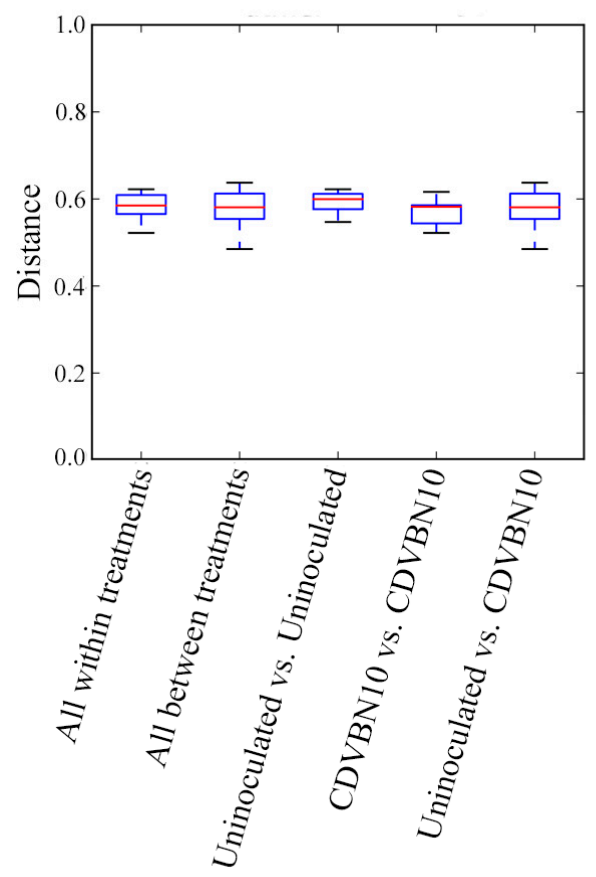

B

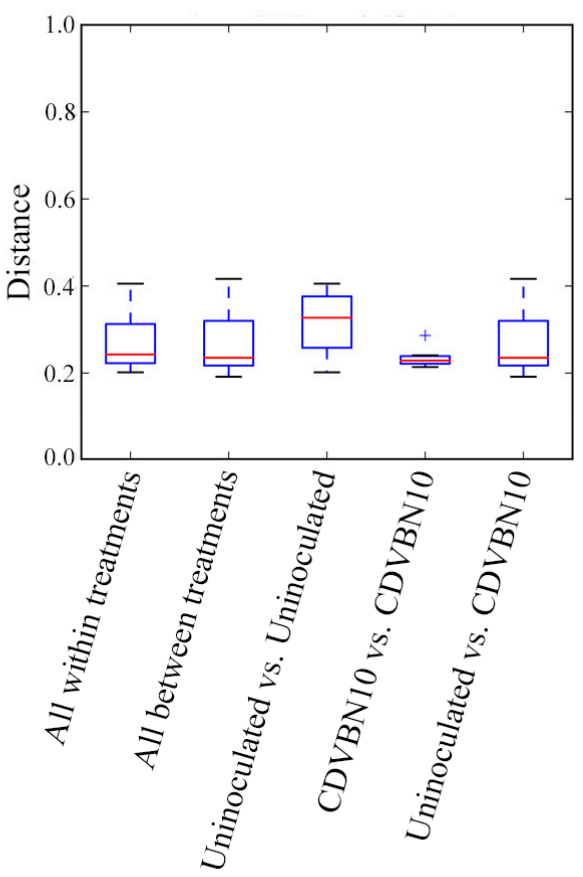

Figure 5. Comparison of beta diversity between sampling sites; (A) boxplots represent the unweighted Unifrac distances; (B) the weighted Unifrac distances. No significant differences were found among all the samples.

Eleven phyla were identified, with the phylum Proteobacteria, with four of the classes present (Alpha-, Beta-, Gamma- and Deltaproteobacteria), being the phylum with the highest relative abundance (27.8\% in uninoculated treatment and $37.1 \%$ in CDVBN10-inoculated). The phyla Bacteroidetes (18.0\% and $19.0 \%$ ) and Verrucomicrobia (5.6\% and $4.6 \%$ ) were the second and the third in relative abundance, respectively (Figure 6A). There are more unassigned sequences in the uninoculated $(42.6 \%)$ than in the CDVBN10-inoculated (34.7\%) treatment. The class Betaproteobacteria is the most abundant within both treatments (18.9\% and $20.9 \%)$, followed by the classes Flavobacteria $(9.9 \%$ and $11.5 \%)$ and Gammaproteobacteria (4.2\% and 5.6\%) (Figure 6B). The orders Burkholderiales $(15.6 \%$ and $18.5 \%)$, families Commamonadecae (8.8\% and $10.6 \%)$ and Oxalobacteraceae $(6.8 \%$ and $7.8 \%)$, genera Polaromonas (2.1\% and 2.6\%) and Janthinobacterium (2.9\% and 3.4\%); and Flavobacteriales $(9.9 \%$ and $11.5 \%)$, the family Flavobacteriaceae ( $9.6 \%$ and $11.2 \%)$, and the genus Flavobacterium $(9.6 \%$ and $11.2 \%)$ are those with the highest relative abundance in both treatments (Figure 6C-E). Other important taxa, such as the order Rhizobiales (2.1\%) or the family Pseudomonadaceae $(0.7 \%)$, showed similar relative abundances in both treatments. Indeed, the genus Pseudomonas, which is supposed to be enriched in the CDVBN10-inoculated treatment, showed the same relative abundance $(0.7 \%)$ in both treatments (Figure 6E). 

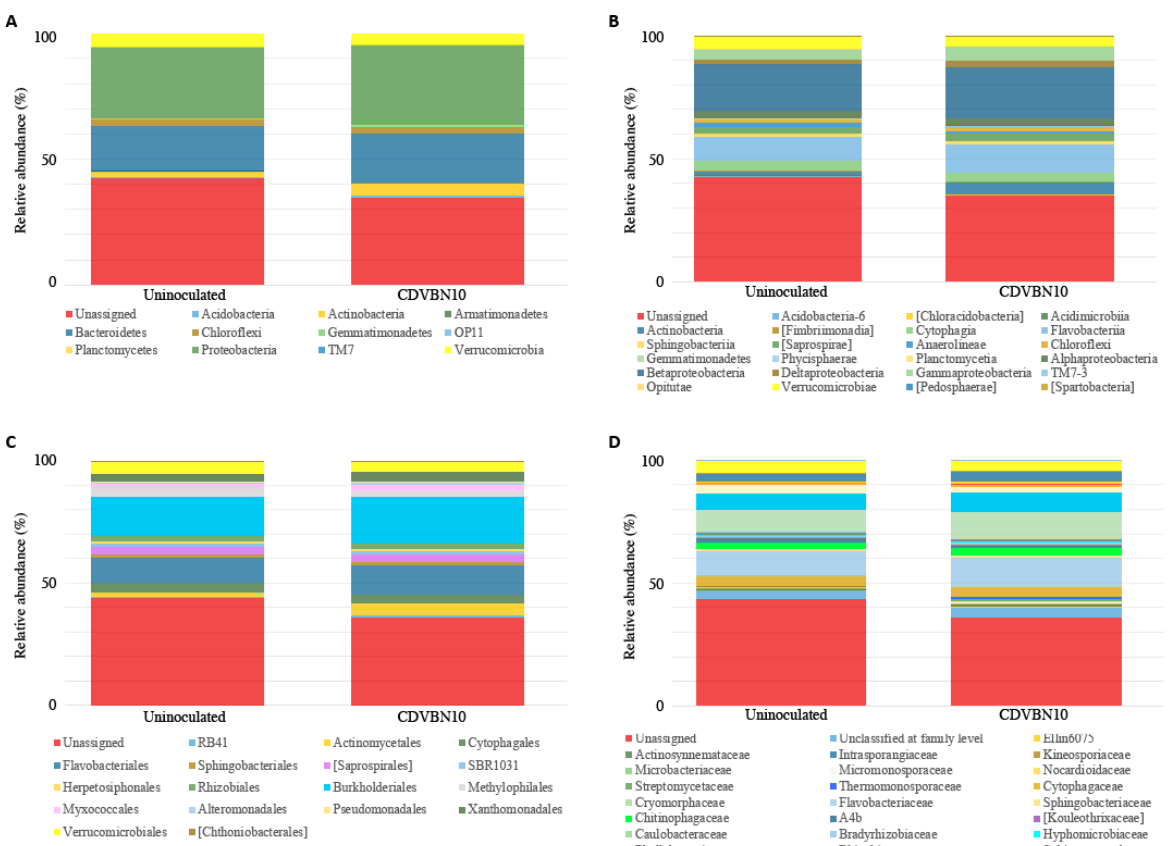

${ }_{100}$
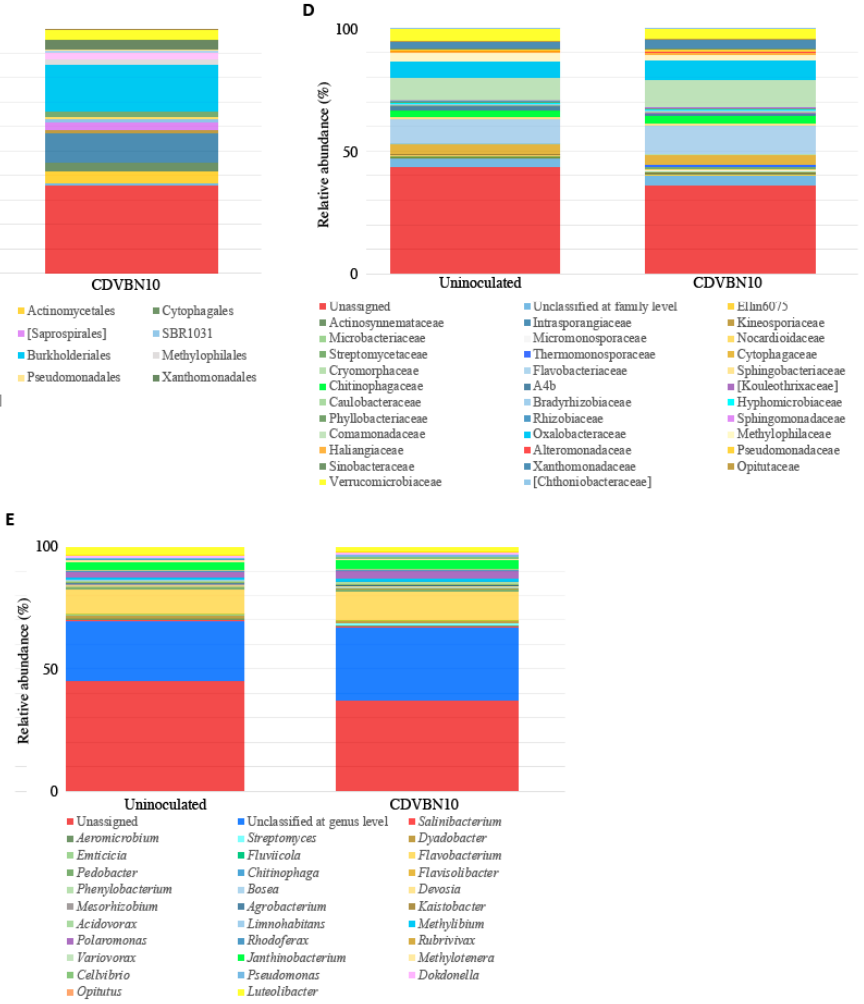

Figure 6. Relative abundance (\%) of bacterial taxa found inside roots of rapeseed plants collected in the uninoculated and CDVBN10 inoculated treatments at different taxonomic levels: (A) phylum, (B) class, (C) order, (D) family and (E) genus. Taxa with relative abundances higher than $0.1 \%$ are represented in the charts.

\section{Discussion}

The results of the present study show a broad biodiversity of bacterial endophytic strains of B. napus roots in two soils from Northwest Spain: the 879F-RAPD fingerprinting, which had been proven to be a useful technique to generate different profiles at the intraspecific level in both Gram-positive and negative bacteria [24,26,52], showed the presence of several different profiles among the isolated strains, and the $16 \mathrm{~S}$ rRNA sequence analysis showed a wide diversity of bacterial species and genera. The dominant genus was Pseudomonas, followed by Pseudoarthrobacter and Bacillus. The genera Pseudomonas and Bacillus appeared in samples from both localities, while all the other genera were location-specific. Strains from the genera Pseudomonas, Bacillus, Rhizobium, Staphylococcus, Acidovorax, Micrococcus, Arthrobacter, Variovorax, Microbacterium, Sphingomonas, Acinetobacter, Devosia and Flavobacterium had already been identified as rapeseed endophytes [19,53-59], while Micromonospora, Massilia, Bosea, Shinella and Agromyces had been found in soil or rhizosphere associated to B. napus roots [57-61]. However, to the best of our knowledge, this is the first report of the association of bacteria from genera Neorhizobium, Microvirga, Herbaspirillum, Dermacoccus, Nocardioides, Isoptericola, Pseudoarthrobacter, Clavibacter and Shigella to B. napus plants, although genera such as Neorhizobium, 
Microvirga and Herbaspirillum are well-known PGP bacteria associated to different plants [62-64]. Considering that the plant endosphere is a much more restricted niche than the rhizosphere, these results show a great biodiversity within the isolated strains, probably due to the use of different isolation media.

Regarding the in vitro PGP potential, $\mathrm{P}$ is an essential plant nutrient and $\mathrm{P}$ deficiency is one of the most important limitations to plant development and crop production, it being estimated that more than 5 billion hectares of land are deficient in P [65]. On the other hand, iron (Fe) is essential for plants, forming part of chlorophyll. Siderophores are molecules that bacteria secrete to solubilize iron, forming a complex ferri-siderophore that can move by diffusion and be returned to the cell or captured by plants [66]. Finally, the production of polysaccharides is an advantage for the strain in order to colonize the plant roots. Amongst those polysaccharides, cellulose is involved in bacterial root colonization and biofilm production-preliminary steps prior to plant growth promotion-and thus, cellulose biosynthesis is important for biofertilizers efficiency [67]. Because of all the mentioned advantages of these PGP bacterial traits, the positive results found for our bacterial isolates suggest the presence of an advantageous endophytic microbiota in rapeseed roots. All isolates except Nocardioides cavernae CDVBN101, Micromonospora coxensis CDVBN102 and Bosea lathyri PDABN26 showed positive results for at least one of the in vitro assayed PGP traits. The best bacteria belonged to the species Pseudomonas thivervalensis, P. poae, P. baetica, P. brassicacearum, Bacillus aryabhattai and Bacillus simplex. Strains belonging to these species have been previously described as PGP of different plants [68-75].

Thus, we tested the capability of representative bacterial strains from those species to promote rapeseed seedling development. The results from these assays suggest that the strains CDVBN10 and CDVBN20, both belonging to the genus Pseudomonas, were the best rapeseed PGPs. The genome analysis of strains CDVBN10 and CDVBN20 showed an interesting genetic PGP potential, as both strains showed positive results in all the PGP traits tested (excepting growth in $\mathrm{N}$-free media). According to the results obtained in the in vitro tests performed in this study and the analyses of other genomes of Pseudomonas strains [37,76-78], we found a great number of genes linked to Fe uptake, metabolism and efflux systems. In addition, in consonance with the in vitro tests and the results found for other Pseudomonas strains [79], both genomes contain gene sequences encoding enzymes that are involved in the solubilization P and K as well as the transport of these elements $[20,24,50]$. In addition, both bacterial genomes contain genes related to IAA biosynthesis. The lack of detection of a complete IAA biosynthetic pathway may be due to the biases of annotating draft genomes. On the other hand, as with other Pseudomonas strains [80], these two bacterial genomes encode the enzyme ACC deaminase; the synthesis of this enzyme would probably confer the plant a better resistance to abiotic stress conditions [81]. The synergy between both IAA synthesis and ACC deaminase activity could lead to a better performance of this plant-bacteria symbiosis [82]. Both bacteria also contain genes related to the biosynthesis of polysaccharides such as a cyclic $\beta$-1,2-glucan synthetase [83] in both genomes and exo genes [84], only in the strain CDVBN10 and genes encoding glycosyl transferases and glycosyl hydrolases, enzymes involved in polysaccharide biosynthesis and biodegradation [85]; polysaccharides have been proved to play a role in biofilm formation and the colonization of root surfaces $[35,86,87]$. Both genomes also have genes encoding transcriptional factors from AraC family, which are known as regulators of many processes including the ones involved in the interchange of signals among bacteria [88] and have been revealed as relevant for rhizosphere competition in rhizobia [89].

Strain CDVBN20 belongs to the species Pseudomonas orientalis, a bacterium not frequently associated with plant microbiomes, this being, to the best of our knowledge, the first time it has been described as a bacterial species associates to $B$. napus. However, the strain CDVBN10 belongs to the species Pseudomonas brassicacearum, which was originally described as a bacterial colonizer of $B$. napus rhizosphere [90]. Moreover, different strains of this species have been isolated as root endophytes from different plants, such as Salvia miltiorrhiza Bunge. [69], Artemisia sp. [91], Lavandula dentata L. [92] and nodules of the legume Sphaerophysa salsula (Pall.) DC. [93]. Some studies also reported how this species promotes the growth of Pisum sativum L. [94], Solanum nigrum L. [95] and Medicago lupulina L. [96] plants. 
Moreover, the genome sequence analyses of other bacterial strains belonging to this species seem to indicate that this bacterium is a good plant growth promoter and a potential biocontrol agent $[97,98]$. Considering the results of this study and previous references of the species, we conclude that the strain P. brassicacearum CDVBN10 has a good potential as rapeseed biofertilizer and we decided to test its performance under field conditions. The results of our trial, performed with no addition of chemical fertilizers, show a significant increase not only in total plant biomass, but also in seed yields compared to the non-inoculated control plants, confirming that this bacterium has an interesting potential to be employed as a biofertilizer for Brassica napus crops, as it has been already for other Pseudomonas species inoculated in field trials [99-101], this being, to the best of our knowledge, the first report of a PGP bacterium with potential to specifically promote rapeseed/canola crops which showed an important yield increase in field trials

Interestingly, despite the significant differences in plant development and yields, the analysis of the biodiversity based on amplicon sequencing showed that there are no significant differences in the root bacterial communities of plants inoculated with the strain Pseudomonas brassicacerarum CDVBN10 nor in the associated functions of this community. In this sense, our results agree with those of Qiao et al. [102], which showed that the inoculation of a PGPB Bacillus strain does not alter the root bacterial microbiome on tomato plants. However, this effect might be strain-specific or context-specific, as suggested by Gadhave et al. [103]; these authors performed several inoculations with different PGPB strains belonging to the genus Bacillus and found that there is an infraspecific variation and competition issues within sprouting broccoli roots. The modulation of root microbiomes by addition of biofertilizers based on beneficial strains and other factors is not well-understood and further studies must be performed to elucidate these effects [104].

According to ecological theories [13,105], most bacteria living as root endophytes probably play important roles for the plant development and survival. Thus, in our opinion, the results obtained in this study are very positive: rapeseed plants from the plots inoculated with the strain CDVBN10 showed a clear benefit from the inoculation and their endophytic root microbiome was not altered by the inoculation, so there was not competition of potentially benefiting members of the plant microbiome.

There is an unexpected result in the PacBio data; we were not able to detect any OTU belonging to the phylum Firmicutes. This is a rare event, taking into account that members of this phylum were found within the root bacterial microbiome of Brassica plants [106]. However, Lay et al. [61] did not find any Firmicutes in canola roots. Some of the amplicon sequences appeared as unclassified at different taxonomic levels, which might be the reason for lacking some taxa in the amplicon sequencing analyses. These results highlight the importance of combining culturomics and metagenomics for biodiversity studies, because whereas isolated strains can be better identified, amplicon sequences allow us to decipher those members of the community which cannot grow in synthetic conditions or are inhibited by other members of the community in the selected growth conditions of the study.

As the bacterial communities associated to plants, both rhizospheric and endophytic, are strongly influenced by many factors [107-109], further studies on different soils and climate conditions should be performed in order to demonstrate the success of this strain as a biofertilizer for rapeseed crops and the lack of alteration of the root microbiome after its addition; furthermore, the best formulation of the strain to be commercialized as a biofertilizer should also be evaluated.

Supplementary Materials: The following are available online at http://www.mdpi.com/2073-4395/10/11/1788/s1, Data sheet; Supplementary Table S1: Beta diversity results. Statistics corresponding to distance boxplots of Figure 5 (from the main text) according to unweighted and weighted Unifrac distances. Supplementary Table S2: Statistic significance of the relatedness of each OTUs with each treatment group (control samples or CDVBN10 inoculated samples). Supplementary Figure S1: Rarefaction curve for observed bacterial OTUs clustering at 97\% $16 \mathrm{~S}$ rRNA sequence similarity. Curves represent number of observed OTUs from the uninoculated (A1-4) and CDVBN10 inoculated (B1-4) treatments. Supplementary Figure S2: Neighbour-joining phylogenetic tree based on the 16S rRNA gene sequences of strain P. brassicacearum CDVBN10 and its closest related type strains. Scale bar = 5 nucleotide (nt) substitutions per $1000 \mathrm{nt}$. 
Author Contributions: Conceptualization, P.G.-F., R.R. and P.F.M.; methodology, A.J.-G. and Z.S.-S.; software, M.K. and Z.S.-S; validation, M.K., E.M. and Z.S.-S.; formal analysis, A.J.-G., Z.S.-S., E.M. and P.G.-F.; investigation, A.J.-G., Z.S.-S., M.K. and E.M.; resources, P.G.-F. and R.R.; data curation, M.K., E.M. and Z.S.-S.; writing-original draft preparation, P.G.-F. and E.M.; writing-review and editing, P.G.-F., E.V. and E.M.; visualization, P.G.-F. and E.M.; supervision, P.G.-F. and P.F.M.; project administration, P.G.-F.; funding acquisition, P.G.-F. All authors have read and agreed to the published version of the manuscript.

Funding: This research was funded by EUROPEAN UNION'S HORIZON 2020 research and innovation programme, grant number 750795. AJG is the recipient of a FPU predoctoral fellowship from the Central Spanish Government and ZSS received a grant from the Junta de Castilla y Leon, Spanish Regional Government. EM acknowledges a FCT contract from the Individual Call to Scientific Employment Stimulus 2017 (CEECIND/00270/2017).

Acknowledgments: Authors thank the Strategic Research Programs for Units of Excellence from Junta de Castilla y León (CLU-2O18-04) for funding equipment and facilities. The authors also thank Jose Antonio García Fernández for granting the land in which the field trial was performed.

Conflicts of Interest: The authors declare no conflict of interest.

\section{References}

1. Wu, W.; Ma, B. Integrated nutrient management (INM) for sustaining crop productivity and reducing environmental impact: A review. Sci. Total Environ. 2015, 512, 415-427. [CrossRef]

2. Adesemoye, A.O.; Torbert, H.A.; Kloepper, J.W. Plant Growth-Promoting Rhizobacteria Allow Reduced Application Rates of Chemical Fertilizers. Microb. Ecol. 2009, 58, 921-929. [CrossRef] [PubMed]

3. Bhardwaj, D.; Ansari, M.W.; Sahoo, R.K.; Tuteja, N. Biofertilizers function as key player in sustainable agriculture by improving soil fertility, plant tolerance and crop productivity. Microb. Cell Fact. 2014, $13,66$. [CrossRef] [PubMed]

4. Mahanty, T.; Bhattacharjee, S.; Goswami, M.; Bhattacharyya, P.; Das, B.; Ghosh, A. Biofertilizers: A potential approach for sustainable agriculture development. Environ. Sci. Pollut. Res. 2017, 24, 3315-3335. [CrossRef] [PubMed]

5. Olanrewaju, O.S.; Glick, B.R.; Babalola, O.O. Mechanisms of action of plant growth promoting bacteria. World J. Microbiol. Biotechnol. 2017, 33, 197. [CrossRef] [PubMed]

6. Menéndez, E.; Garcia-Fraile, P. Plant probiotic bacteria: Solutions to feed the world. AIMS Microbiol. 2017, 3, 502-524. [CrossRef] [PubMed]

7. Gaiero, J.R.; McCall, C.A.; Thompson, K.A.; Day, N.J.; Best, A.S.; Dunfield, K.E. Inside the root microbiome: Bacterial root endophytes and plant growth promotion. Am. J. Bot. 2013, 100, 1738-1750. [CrossRef]

8. Santoyo, G.; Moreno-Hagelsieb, G.; del Carmen Orozco-Mosqueda, M.; Glick, B.R. Plant growth-promoting bacterial endophytes. Microbiol. Res. 2016, 183, 92-99. [CrossRef]

9. Gopal, M.; Gupta, A. Microbiome selection could spur next-generation plant breeding strategies. Front. Microbiol. 2016, 7, 1971. [CrossRef]

10. Velázquez, E.; García-Fraile, P.; Ramírez-Bahena, M.H.; Rivas, R.; Martínez-Molina, E. Bacteria Involved in Nitrogen-Fixing Legume Symbiosis: Current Taxonomic Perspective. In Microbes for Legume Improvement; Springer: Vienna, Austria, 2010; pp. 1-5.

11. Brundrett, M.C.; Tedersoo, L. Evolutionary history of mycorrhizal symbioses and global host plant diversity. New Phytol. 2018, 220, 1108-1115. [CrossRef]

12. Clear, M.R.; Hom, E.F. The evolution of symbiotic plant-microbe signaling. Ann. Plant. Rev. Online 2019, 2, 1-52. [CrossRef]

13. Vorholt, J.A.; Vogel, C.; Carlström, C.I.; Müller, D.B. Establishing causality: Opportunities of synthetic communities for plant microbiome research. Cell Host Microb. 2017, 22, 142-155. [CrossRef] [PubMed]

14. Etesami, H.; Alikhani, H.A. Rhizosphere and endorhiza of oilseed rape (Brassica napus L.) plant harbor bacteria with multifaceted beneficial effects. Biol. Cont. 2016, 94, 11-24. [CrossRef]

15. Card, S.D.; Hume, D.E.; Roodi, D.; McGill, C.R.; Millner, J.P.; Johnson, R.D. Beneficial endophytic microorganisms of Brassica-A review. Biol. Control. 2015, 90, 102-112. [CrossRef]

16. Rathore, R.; Germaine, K.J.; Forristal, P.D.; Spink, J.; Dowling, D. Meta-Omics Approach to Unravel the Endophytic Bacterial Communities of Brassica napus and Other Agronomically Important Crops. In Endophytes for a Growing World; Hodkinson, T.R., Ed.; Cambridge University Press: Cambridge, UK, 2019; p. 232. 
17. Farina, R.; Beneduzi, A.; Ambrosini, A.; de Campos, S.B.; Lisboa, B.B.; Wendisch, V. Diversity of plant growth-promoting rhizobacteria communities associated with the stages of canola growth. Appl. Soil Ecol. 2012, 55, 44-52. [CrossRef]

18. Bertrand, H.; Nalin, R.; Bally, R.; Cleyet-Marel, J.C. Isolation and identification of the most efficient plant growth-promoting bacteria associated with canola (Brassica napus). Biol. Fertil. Soils 2001, 33, 152-156. [CrossRef]

19. Sheng, X.F.; Xia, J.J.; Jiang, C.Y.; He, L.Y.; Qian, M. Characterization of heavy metal-resistant endophytic bacteria from rape (Brassica napus) roots and their potential in promoting the growth and lead accumulation of rape. Environ. Pollut. 2008, 156, 1164-1170. [CrossRef]

20. Etesami, H.; Emami, S.; Alikhani, H.A. Potassium solubilizing bacteria (KSB): Mechanisms, promotion of plant growth and future prospects A review. J. Soil Sci. Plant. Nutr. 2017, 17, 897-911. [CrossRef]

21. Puri, A.; Padda, K.P.; Chanway, C.P. Evidence of nitrogen fixation and growth promotion in canola (Brassica napus L.) by an endophytic diazotroph Paenibacillus polymyxa P2b-2R. Biol. Fertil. Soils 2016, 52, 119-125. [CrossRef]

22. Lally, R.D.; Galbally, P.; Moreira, A.S.; Spink, J.; Ryan, D.; Germaine, K.J. Application of endophytic Pseudomonas fluorescens and a bacterial consortium to Brassica napus can increase plant height and biomass under greenhouse and field conditions. Front. Plant. Sci. 2017, 8, 2193. [CrossRef]

23. Petrova, S.N.; Andronov, E.E.; Belimov, A.A.; Beregovaya, Y.V.; Denshchikov, V.A.; Minakov, D.L. Prokaryotic Community Structure in the Rapeseed (Brassica napus L.) Rhizosphere Depending on Addition of 1-Aminocyclopropane-1-Carboxylate-Utilizing Bacteria. Microbiology 2020, 89, 115-121. [CrossRef]

24. Bruto, M.; Prigent-Combaret, C.; Muller, D.; Moënne-Loccoz, Y. Analysis of genes contributing to plant-beneficial functions in plant growth-promoting rhizobacteria and related Proteobacteria. Sci. Rep. 2014, 4, 6261. [CrossRef] [PubMed]

25. López-Mondéjar, R.; Kostovčík, M.; Lladó, S.; Carro, L.; García-Fraile, P. Exploring the Plant Microbiome through Multi-Omics Approaches. In Probiotics in Agroecosystem; Springer: Singapore, 2017; pp. $233-268$.

26. Igual, J.M.; Valverde, A.; Rivas, R.; Mateos, P.F.; Rodríguez-Barrueco, C.; Martínez-Molina, E. Genomic Fingerprinting of Frankia Strains by PCR-Based Techniques. Assessment of a Primer Based on the Sequence of 16S rRNA Gene of Escherichia coli. In Frankia Symbiosis; Normand, P., Pawlowski, K., Dawson, J.I., Eds.; Springer: Dordrecht, The Netherland, 2003; pp. 115-123.

27. Rivas, R.; Garcia-Fraile, P.; Peix, A.; Mateos, P.F.; Martínez-Molina, E.; Velazquez, E. Alcanivorax balearicus sp. nov., isolated from Lake Martel. Int. J. Syst. Evol. Microbiol. 2007, 57, 1331-1335. [CrossRef] [PubMed]

28. Poveda, J.; Jiménez-Gómez, A.; Saati-Santamaría, Z.; Usategui-Martín, R.; Rivas, R.; García-Fraile, P. Mealworm frass as a potential biofertilizer and abiotic stress tolerance-inductor in plants. Appl. Soil Ecol. 2019, 142, 110-122. [CrossRef]

29. Altschul, S.F.; Madden, T.L.; Schäffer, A.A.; Zhang, J.; Zhang, Z.; Miller, W. Gapped BLAST and PSI-BLAST: A new generation of protein database search programs. Nucleic Acids Res. 1997, 25, 3389-3402. [CrossRef]

30. Chun, J.; Lee, J.H.; Jung, Y.; Kim, M.; Kim, S.; Kim, B.K. EzTaxon: A web-based tool for the Identification of prokaryotes based on $16 \mathrm{~S}$ ribosomal RNA gene sequences. Int. J. Syst. Evol. Microbiol. 2007, 57, 2259-2261. [CrossRef]

31. Jiménez-Gómez, A.; Saati-Santamaría, Z.; Igual, J.M.; Rivas, R.; Mateos, P.F.; García-Fraile, P. Genome Insights into the Novel Species Microvirga brassicacearum, a Rapeseed Endophyte with Biotechnological Potential. Microorganisms 2019, 7, 354. [CrossRef]

32. Schwyn, B.; Neilands, J.B. Universal chemical assay for the detection and determination of siderophores. Anal. Biochem. 1987, 160, 47-56. [CrossRef]

33. Alexander, D.B.; Zuberer, D.A. Use of Chrome Azurol S reagents to evaluate siderophore production by rhizosphere bacteria. Biol. Fertil. Soils 1991, 12, 39-45. [CrossRef]

34. Pikovskaya, R.I. Mobilization of phosphorus in soil connection with the vital activity of some microbial species. Microbiologiya 1948, 17, 362-370.

35. Robledo, M.; Rivera, L.; Jiménez-Zurdo, J.I.; Rivas, R.; Dazzo, F.; Velázquez, E.; Mateos, P.F. Role of Rhizobium endoglucanase $\mathrm{CelC} 2$ in cellulose biosynthesis and biofilm formation on plant roots and abiotic surfaces. Microb. Cell Fact. 2012, 11, 125. [CrossRef] [PubMed]

36. Khalid, A.; Arshad, M.; Zahir, Z.A. Screening plant growth-promoting rhizobacteria for improving growth and yield of wheat. J. Appl. Microbiol. 2004, 96, 473-480. [CrossRef] [PubMed] 
37. Saati-Santamaría, Z.; López-Mondéjar, R.; Jiménez-Gómez, A.; Díez-Méndez, A.; Větrovský, T.; Igual, J.M.; Garcia-Fraile, P. Discovery of phloeophagus beetles as a source of Pseudomonas strains that produce potentially new bioactive substances and description of Pseudomonas bohemica sp. nov. Front. Microbiol. 2018, 9. [CrossRef] [PubMed]

38. Zerbino, D.R.; Birney, E. Velvet: Algorithms for de novo short read assembly using de Bruijn graphs. Genome Res. 2008, 18, 821-829. [CrossRef] [PubMed]

39. Aziz, R.K.; Bartels, D.; Best, A.A.; DeJongh, M.; Disz, T.; Edwards, R.A. The RAST Server: Rapid annotations using subsystems technology. BMC Genomics 2008, 9, 75. [CrossRef]

40. Dellavalle, N.B. Determination of Specific Conductance in Supernatant 1:2 soil:water solution. In Handbook on Reference Methods for Soil Analysis; Council, Inc.: Athens, GA, USA, 1992; pp. 44-50.

41. Větrovský, T.; Baldrian, P.; Morais, D. SEED 2: A user-friendly platform for amplicon high-throughput sequencing data analyses. Bioinformatics 2018, 34, 2292-2294. [CrossRef] [PubMed]

42. Caporaso, J.G.; Kuczynski, J.; Stombaugh, J.; Bittinger, K.; Bushman, F.D.; Costello, E.K. QIIME allows analysis of high-throughput community sequencing data. Nat. Methods 2010, 7, 335. [CrossRef]

43. DeSantis, T.Z.; Hugenholtz, P.; Larsen, N.; Rojas, M.; Brodie, E.L.; Keller, K. Greengenes, a chimera-checked $16 \mathrm{~S}$ rRNA gene database and workbench compatible with ARB. Appl. Environ. Microbiol. 2006, 72, 5069-5072. [CrossRef]

44. Edgar, R.C.; Haas, B.J.; Clemente, J.C.; Quince, C.; Knight, R. UCHIME improves sensitivity and speed of chimera detection. Bioinformatics 2011, 27, 2194-2200. [CrossRef]

45. Kruskal, W.H.; Wallis, W.A. Use of ranks in one-criterion variance analysis. J. Am. Stat. Assoc. 1952, 47, 583-621. [CrossRef]

46. Benjamini, Y.; Hochberg, Y. Controlling the false discovery rate: A practical and powerful approach to multiple testing. J. R. Stat. Soc. Ser. B 1995, 57, 289-300. [CrossRef]

47. Bonferroni, C.E. Teoria Statistica Delle Classi e Calcolo Delle Probabilità; Libreria Internazionale Seeber: Florence, Italy, 1936.

48. Landau, S.; Rabe-Hesketh, S. Software review: StatView for windows, version 5.0. Stat. Methods Med. Res. 1999, 8, 337-341. [CrossRef] [PubMed]

49. Santos-Beneit, F. The Pho regulon: A huge regulatory network in bacteria. Front. Microbiol. 2015, 6, 402. [CrossRef] [PubMed]

50. Epstein, W. The roles and regulation of potassium in bacteria. Prog. Nucleic Acid Res. 2003, 75, $293-320$.

51. Meyer, J.M. Pyoverdine Siderophores as Taxonomic and Phylogenic Markers. Pseudomonas 2010, 201-233. [CrossRef]

52. Rivas, R.; Peix, A.; Mateos, P.F.; Trujillo, M.E.; Martínez-Molina, E.; Velázquez, E. Biodiversity of populations of phosphate solubilizing rhizobia that nodulates chickpea in different Spanish soils. Plant. Soil 2006, 287, 23-33. [CrossRef]

53. Germida, J.J.; Siciliano, S.D.; Renato de Freitas, J.; Seib, A.M. Diversity of root-associated bacteria associated with field-grown canola (Brassica napus L.) and wheat (Triticum aestivum L.). FEMS Microbiol. Ecol. 1998, 26, 43-50. [CrossRef]

54. Dunfield, K.E.; Germida, J.J. Diversity of bacterial communities in the rhizosphere and root interior of field-grown genetically modified Brassica napus. FEMS Microbiol. Ecol. 2001, 38, 1-9. [CrossRef]

55. Granér, G.; Persson, P.; Meijer, J.; Alström, S. A study on microbial diversity in different cultivars of Brassica napus in relation to its wilt pathogen, Verticillium longisporum. FEMS Microbiol. Lett. 2003, 224, 269-276. [CrossRef]

56. Zhang, Y.F.; He, L.Y.; Chen, Z.J.; Wang, Q.Y.; Qian, M.; Sheng, X.F. Characterization of ACC deaminase-producing endophytic bacteria isolated from copper-tolerant plants and their potential in promoting the growth and copper accumulation of Brassica napus. Chemosphere 2011, 83, 57-62. [CrossRef]

57. Croes, S.; Weyens, N.; Janssen, J.; Vercampt, H.; Colpaert, J.V.; Carleer, R. Bacterial communities associated with Brassica napus L. grown on trace element-contaminated and non-contaminated fields: A genotypic and phenotypic comparison. Microb. Biotechnol. 2013, 6, 371-384. [CrossRef] [PubMed]

58. Montalbán, B.; Croes, S.; Weyens, N.; Lobo, M.C.; Pérez-Sanz, A.; Vangronsveld, J. Characterization of bacterial communities associated with Brassica napus L. growing on a Zn-contaminated soil and their effects on root growth. Int. J. Phytoremediat. 2016, 18, 985-993. [CrossRef] 
59. Gkarmiri, K.; Mahmood, S.; Ekblad, A.; Alström, S.; Högberg, N.; Finlay, R. Identifying the active microbiome associated with roots and rhizosphere soil of oilseed rape. Appl. Environ. Microbiol. 2017, 83, e01938-17. [CrossRef] [PubMed]

60. Larcher, M.; Rapior, S.; Cleyet-Marel, J.C. Bacteria from the rhizosphere and roots of Brassica napus influence its root growth promotion by Phyllobacterium brassicacearum. Acta Bot. Gallica 2008, 155, 355-366. [CrossRef]

61. Lay, C.Y.; Bell, T.H.; Hamel, C.; Harker, K.N.; Mohr, R.; Greer, C.W. Canola Root-Associated Microbiomes in the Canadian Prairies. Front. Microbiol. 2018, 9, 1188. [CrossRef] [PubMed]

62. Chen, L.; He, L.Y.; Wang, Q.; Sheng, X.F. Synergistic effects of plant growth-promoting Neorhizobium huautlense T1-17 and immobilizers on the growth and heavy metal accumulation of edible tissues of hot pepper. J. Hazard. Mater. 2016, 312, 123-131. [CrossRef]

63. Msaddak, A.; Rejili, M.; Durán, D.; Rey, L.; Imperial, J.; Palacios, J.M. Members of Microvirga and Bradyrhizobium genera are native endosymbiotic bacteria nodulating Lupinus luteus in Northern Tunisian soils. FEMS Microbiol. Ecol. 2017, 93. [CrossRef] [PubMed]

64. Dall'Asta, P.; Velho, A.C.; Pereira, T.P.; Stadnik, M.J.; Arisi, A.C.M. Herbaspirillum seropedicae promotes maize growth but fails to control the maize leaf anthracnose. Physiol. Mol. Biol. Plant. 2019, 25, 167-176. [CrossRef]

65. Mouazen, A.M.; Kuang, B. On-line visible and near infrared spectroscopy for in-field phosphorus management. Soil Tillage Res. 2016, 155, 471-477. [CrossRef]

66. Beneduzi, A.; Ambrosini, A.; Passaglia, L.M.P. Plant growth-promoting rhizobacteria (PGPR): Their potential as antagonists and biocontrol agents. Genet. Mol. Biol. 2012, 35, 1044-1051. [CrossRef]

67. Jiménez-Gómez, A.; Flores-Félix, J.D.; García-Fraile, P.; Mateos, P.F.; Menéndez, E.; Velázquez, E.; Rivas, R. Probiotic activities of Rhizobium laguerreae on growth and quality of spinach. Sci. Rep. 2018, 8, 295. [CrossRef] [PubMed]

68. Yang, P.X.; Li, M.A.; Ming-Hui, C.; Jia-Qin, X.I.; Feng, H.E.; Chang-Qun, D. Phosphate solubilizing ability and phylogenetic diversity of bacteria from P-rich soils around Dianchi Lake drainage area of China. Pedosphere 2012, 22, 707-716. [CrossRef]

69. Li, X.J.; Tang, H.Y.; Duan, J.L.; Gao, J.M.; Xue, Q.H. Bioactive alkaloids produced by Pseudomonas brassicacearum subsp. neoaurantiaca, an endophytic bacterium from Salvia miltiorrhiza. Nat. Prod. Res. 2013, 27, 496-499. [CrossRef] [PubMed]

70. Wang, X.; Mavrodi, D.V.; Ke, L.; Mavrodi, O.V.; Yang, M.; Thomashow, L.S. Biocontrol and plant growth-promoting activity of rhizobacteria from Chinese fields with contaminated soils. Microb. Biotechnol. 2015, 8, 404-418. [CrossRef] [PubMed]

71. Matthijs, S.; Brandt, N.; Ongena, M.; Achouak, W.; Meyer, J.M.; Budzikiewicz, H. Pyoverdine and histicorrugatin-mediated iron acquisition in Pseudomonas thivervalensis. Biometals 2016, 29, 467-485. [CrossRef] [PubMed]

72. Chakraborty, B.N.; Allay, S.; Chakraborty, A.P.; Chakraborty, U. PGPR in managing root rot disease and enhancing growth in mandarin (Citrus reticulata Blanco.) seedlings. J. Hortic. Sci. 2017, 11, 104-115.

73. Ortiz-Ojeda, P.; Ogata-Gutiérrez, K.; Zúñiga-Dávila, D. Evaluation of plant growth promoting activity and heavy metal tolerance of psychrotrophic bacteria associated with maca (Lepidium meyenii Walp.) rhizosphere. AIMS Microbiol. 2017, 3, 279-292. [CrossRef]

74. Park, Y.G.; Mun, B.G.; Kang, S.M.; Hussain, A.; Shahzad, R.; Seo, C.W. Bacillus aryabhattai SRB02 tolerates oxidative and nitrosative stress and promotes the growth of soybean by modulating the production of phytohormones. PLoS ONE 2017, 12, e0173203. [CrossRef]

75. Naili, F.; Neifar, M.; Elhidri, D.; Cherif, H.; Bejaoui, B.; Aroua, M. Optimization of the effect of PGPR-based biofertlizer on wheat growth and yield. Biom. Biostat. Int. J. 2018, 7, 226-232. [CrossRef]

76. Cézard, C.; Farvacques, N.; Sonnet, P. Chemistry and biology of pyoverdines, Pseudomonas primary siderophores. Curr. Med. Chem. 2015, 22, 165-186. [CrossRef]

77. Trapet, P.; Avoscan, L.; Klinguer, A.; Pateyron, S.; Citerne, S.; Chervin, C. The Pseudomonas fluorescens siderophore pyoverdine weakens Arabidopsis thaliana defense in favor of growth in iron-deficient conditions. Plant. Physiol. 2016, 171, 675-693. [CrossRef] [PubMed]

78. Kuzmanović, N.; Eltlbany, N.; Ding, G.; Baklawa, M.; Min, L.; Wei, L. Analysis of the genome sequence of plant beneficial strain Pseudomonas sp. RU47. J. Biotechnol. 2018, 281, 183-192. [CrossRef] [PubMed] 
79. Singh, S.K.; Singh, P.P.; Gupta, A.; Singh, A.K.; Keshri, J. Tolerance of Heavy Metal Toxicity Using PGPR Strains of Pseudomonas Species. In PGPR Amelioration in Sustainable Agriculture; Singh, K., Ed.; Woodhead Publishing: Sawston, UK, 2019; pp. 239-252.

80. Nascimento, F.X.; Rossi, M.J.; Glick, B.R. Ethylene and 1-Aminocyclopropane-1-carboxylate (ACC) in plant-bacterial interactions. Front. Plant. Sci. 2018, 9, 114. [CrossRef] [PubMed]

81. Glick, B.R.; Todorovic, B.; Czarny, J.; Cheng, Z.; Duan, J.; McConkey, B. Promotion of plant growth by bacterial ACC deaminase. Crit. Rev. Plant Sci. 2007, 26, 227-242. [CrossRef]

82. Ciocchini, A.E.; Roset, M.S.; Briones, G.; de Iannino, N.I.; Ugalde, R.A. Identification of active site residues of the inverting glycosyltransferase $C$ gs required for the synthesis of cyclic $\beta$-1, 2-glucan, a Brucella abortus virulence factor. Glycobiology 2006, 16, 679-691. [CrossRef] [PubMed]

83. Glick, B.R. Bacteria with ACC deaminase can promote plant growth and help to feed the world. Microbiol. Res. 2014, 169, 30-39. [CrossRef] [PubMed]

84. Skorupska, A.; Janczarek, M.; Marczak, M.; Mazur, A.; Król, J. Rhizobial exopolysaccharides: Genetic control and symbiotic functions. Microb. Cell Fact. 2006, 5, 7. [CrossRef]

85. Henrissat, B.; Sulzenbacher, G.; Bourne, Y. Glycosyltransferases, glycoside hydrolases: Surprise. Curr. Opin. Struct. Biol. 2008, 18, 527-533. [CrossRef]

86. Rodríguez-Navarro, D.N.; Dardanelli, M.S.; Ruíz-Saínz, J.E. Attachment of bacteria to the roots of higher plants. FEMS Microbiol. Lett. 2007, 272, 127-136. [CrossRef]

87. Bogino, P.; Oliva, M.; Sorroche, F.; Giordano, W. The role of bacterial biofilms and surface components in plant-bacterial associations. Int. J. Mol. Sci. 2013, 14, 15838-15859. [CrossRef]

88. Yang, J.; Tauschek, M.; Robins-Browne, R.M. Control of bacterial virulence by AraC-like regulators that respond to chemical signals. Trends Microbiol. 2011, 19, 128-135. [CrossRef] [PubMed]

89. Garcia-Fraile, P.; Seaman, J.C.; Karunakaran, R.; Edwards, A.; Poole, P.S.; Downie, J.A. Arabinose and protocatechuate catabolism genes are important for growth of Rhizobium leguminosarum biovar viciae in the pea rhizosphere. Plant Soil 2015, 390, 251-264. [CrossRef]

90. Achouak, W.; Sutra, L.; Heulin, T.; Meyer, J.M.; Fromin, N.; Degraeve, S. Pseudomonas brassicacearum sp. nov. and Pseudomonas thivervalensis sp. nov., two root-associated bacteria isolated from Brassica napus and Arabidopsis thaliana. Int. J. Syst. Evol. Microbiol. 2000, 50, 9-18. [CrossRef] [PubMed]

91. Chung, B.S.; Aslam, Z.; Kim, S.W.; Kim, G.G.; Kang, H.S.; Ahn, J.W. A bacterial endophyte, Pseudomonas brassicacearum YC5480, isolated from the root of Artemisia sp. producing antifungal and phytotoxic compounds. Plant Pathol. J. 2008, 24, 461-468. [CrossRef]

92. Pereira, S.I.A.; Monteiro, C.; Vega, A.L.; Castro, P.M. Endophytic culturable bacteria colonizing Lavandula dentata L. plants: Isolation, characterization and evaluation of their plant growth-promoting activities. Ecol. Eng. 2016, 87, 91-97. [CrossRef]

93. Deng, Z.S.; Zhao, L.F.; Kong, Z.Y.; Yang, W.Q.; Lindström, K.; Wang, E.T. Diversity of endophytic bacteria within nodules of the Sphaerophysa salsula in different regions of Loess Plateau in China. FEMS Microbiol. Ecol. 2011, 76, 463-475. [CrossRef] [PubMed]

94. Safronova, V.I.; Stepanok, V.V.; Engqvist, G.L.; Alekseyev, Y.V.; Belimov, A.A. Root-associated bacteria containing 1-aminocyclopropane-1-carboxylate deaminase improve growth and nutrient uptake by pea genotypes cultivated in cadmium supplemented soil. Biol. Fertil. Soil 2006, 42, 267-272. [CrossRef]

95. Long, H.H.; Schmidt, D.D.; Baldwin, I.T. Native bacterial endophytes promote host growth in a species-specific manner; phytohormone manipulations do not result in common growth responses. PLOS ONE 2008, 3, e2702. [CrossRef]

96. Kong, Z.; Deng, Z.; Glick, B.R.; Wei, G.; Chou, M. A nodule endophytic plant growth-promoting Pseudomonas and its effects on growth, nodulation and metal uptake in Medicago lupulina under copper stress. Ann. Microbiol. 2017, 67, 49-58. [CrossRef]

97. Zachow, C.; Müller, H.; Monk, J.; Berg, G. Complete genome sequence of Pseudomonas brassicacearum strain L13-6-12, a biological control agent from the rhizosphere of potato. Stand. Genomic Sci. 2017, 12, 6. [CrossRef]

98. Zengerer, V.; Schmid, M.; Bieri, M.; Müller, D.C.; Remus-Emsermann, M.N.; Ahrens, C.H. Pseudomonas orientalis F9: A potent antagonist against phytopathogens with phytotoxic effect in the apple flower. Front. Microbiol. 2018, 9, 145. [CrossRef] [PubMed] 
99. Madani, H.; Malboobi, M.A.; Bakhshkelarestaghi, K.; Stoklosa, A. Biological and Chemical Phosphorus Fertilizers Effect on Yield and P Accumulation in Rapeseed (Brassica napus L.). Not. Bot. Hortic. Agrobot. Cluj-Napoca 2012, 40, 210-214. [CrossRef]

100. Mohammadi, K.; Rokhzadi, A. An integrated fertilization system of canola (Brassica napus L.) production under different crop rotations. Ind. Crops Prod. 2012, 37, 264-269. [CrossRef]

101. Valetti, L.; Iriarte, L.; Fabra, A. Growth promotion of rapeseed (Brassica napus) associated with the inoculation of phosphate solubilizing bacteria. Appl. Soil Ecol. 2018, 132, 1-10. [CrossRef]

102. Qiao, J.; Yu, X.; Liang, X.; Liu, Y.; Borriss, R.; Liu, Y. Addition of plant-growth-promoting Bacillus subtilis PTS-394 on tomato rhizosphere has no durable impact on composition of root microbiome. BMC Microbiol. 2017, 17, 131. [CrossRef] [PubMed]

103. Gadhave, K.R.; Devlin, P.F.; Ebertz, A.; Ross, A.; Gange, A.C. Soil inoculation with Bacillus spp. modifies root endophytic bacterial diversity, evenness, and community composition in a context-specific manner. Microb. Ecol. 2018, 76, 741-750. [CrossRef] [PubMed]

104. Compant, S.; Samad, A.; Faist, H.; Sessitsch, A. A review on the plant microbiome: Ecology, functions and emerging trends in microbial application. J. Adv. Res. 2019, 19, 29-37. [CrossRef]

105. Van der Heijden, M.G.; Hartmann, M. Networking in the plant microbiome. PLoS Biol. 2016, 14, e1002378. [CrossRef]

106. Cordero, J.; de Freitas, J.R.; Germida, J.J. Bacterial microbiome associated with the rhizosphere and root interior of crops in Saskatchewan, Canada. Can. J. Microbiol. 2020, 66, 71-85. [CrossRef]

107. Berg, G.; Smalla, K. Plant species and soil type cooperatively shape the structure and function of microbial communities in the rhizosphere. FEMS Microbiol. Ecol. 2009, 68, 1-13. [CrossRef]

108. Hartmman, K.; Tringe, S.G. Interactions between plants and soil shaping the root microbiome under abiotic stress. Biochem. J. 2019, 476, 2705-2724. [CrossRef] [PubMed]

109. Naylor, D.; DeGraaf, S.; Purdom, E.; Coleman-Derr, D. Drought and host selection influence bacterial community dynamics in the grass root microbiome. ISME J. 2017, 11, 2691-2704. [CrossRef] [PubMed]

Publisher's Note: MDPI stays neutral with regard to jurisdictional claims in published maps and institutional affiliations.

(C) 2020 by the authors. Licensee MDPI, Basel, Switzerland. This article is an open access article distributed under the terms and conditions of the Creative Commons Attribution (CC BY) license (http://creativecommons.org/licenses/by/4.0/). 